\title{
Lyon, das fontes escritas ao SIG histórico - método e exemplos de aplicação
}

\author{
[ Lyon, written historical source GIS - method and examples of developments
}

\section{Bernard Gauthiez ${ }^{\mathrm{I}}$}

\begin{abstract}
Texto traduzido do francês por Eliane Kuvasney. Este artigo é um desdobramento de parte do artigo: GAUTHIEZ, B.; ZELLER, O. Lyons, the spatial analysis of a City in the I7th and I8th Centuries. Locating and Crossing data in a GIS Built from Written Sources. In: RAU, S.; SCHÖNHERR, E. (Ed.). Mapping spatial relations, their perceptions and dynamics. Cham/Heidelberg/New York/Dordrecht/Londres: Springer, 20I4, p. 97-II8
\end{abstract}

\begin{abstract}
RESUMO - O SIG histórico de Lyon foi desenvolvido a partir do final da década de I990, com o objetivo de chegar a um novo entendimento da transformação dos espaços urbanos e sociais pela espacialização dos dados à escala dos edifícios. Pensamos que, por tal salto na precisão de um fator Ioo, de uma subdivisão por 36 bairros para uma por 3.500 edifícios no período moderno, o mapeamento levaria a novas perspectivas e novos resultados a história urbana. Isso envolveu o trabalho ao longo de dois séculos de documentos de arquivo, registros de impostos, censos, licenças de construção, alterações de propriedade, a fim de criar bases de dados criticamente pesquisados, seguidos por layers de SIG vetorizados. Foi necessário desenvolver um método para revelar a espacialidade implícita dessas fontes escritas, estabelecer um mapeamento da topografia, permitido pela reconstrução cuidadosa do padrão de trama da cidade, juntamente com sua variação antes de I80o, e levar em conta a transformação do espaço, estudado na escala real de investimentos individuais, através das licenças de construção verificadas com as construções ainda existentes, e o registro administrativo. PALAVRAS-CHAVE - SIG histórico; geografia histórica; licenças de constru-
\end{abstract}

ção; imóveis; indústria da seda; Lyon. • ABSTRACT - The Lyons historical GIS was developed from the end of the I990s whit the goal to reach a new understanding of the transformation of urban and social spaces by spatializing data at the buildings scale. We thought that by such a jump in precision of a factor 100, from a subdivision by 36 quarters to one by 3,500 buildings in the modern period, the mapping would lead to new perspectives and results in urban history. This involved working through two centuries of archival records, taxes registers, censuses, building permits, property changes in order to create critically researched data bases followed by vector GIS layers. It was necessary develop a method to reveal the implicit spatiality of these written sources, to establish a mapping topography, allowed by a careful and geometrically checked reconstruction of the city's plot pattern together with its variation before $I 800$, and to take into account the space transformation, studied at the actual scale of individual investments, owing to the building permits checked with the still extant constructions, and the administrative record. KEYWORDS - Historical SIG; historical geography; authorizations to build; buildings; silk trade; Lyons.

Recebido em 2 I de março de 2016

Aprovado em 25 de julho de 2016

GAUTHIEZ, Bernard. Lyon, das fontes escritas ao SIG histórico - método e exemplos de aplicação. Revista do Instituto de Estudos Brasileiros, Brasil, n. 64, p. 2I-50, ago. 2016.

DOI: http://dx.doi.org/Io.II606/issn.23I6-90IX.voi64p2I-50

I Université Jean Moulin Lyon 3 (Lyon, França). 


\section{INTRODUÇão}

O Sistema de Informações Geográficas - SIG histórico de Lyon foi concebido no fim dos anos I990 para utilizar fontes de arquivos pouco ou nada exploradas anteriormente ${ }^{2}$, em especial as licenças de construção dadas pela administração municipal, o Consulat. Tratava-se, em primeiro lugar, de estudar a transformação material da cidade, depois, o seu espaço social. O número dessas licenças de construção, praticamente todas preservadas entre I6I7 e I763, é de cerca de 8 mil, entre as quais 2.535 construções novas e reconstruções, e 840 sobre-elevações de um ou dois andares. Os outros se referem a modificações de fachada, abertura ou fechamento de janelas e de portas, estabelecimento de dutos de água privados (adutoras de água ou esgotos) sob a via pública, e situações outras semelhantes³. O primeiro objetivo desse projeto era cartografar a evolução de uma cidade à escala dos seus elementos mais finos, em outras palavras, os quanta de modificação da estrutura, a fim de melhorar a compreensão dos processos envolvidos. A transformação do urban fabric (a cidade material) não é contínua, mas é feita da acumulação dessas pequenas mudanças no quadro geral de operações de urbanismo de dimensão variável. A identificação dessas operações de urbanismo e a sua cartografia própria também são integradas ao SIG.

Esse projeto exigiu percorrer etapas epistemológicas importantes em relação à natureza dos objetos a cartografar, tendo as unidades de construção e as operações de urbanismo claramente definidas 4 .

Outro objetivo, tornado possível pela cartografia das fontes escritas e do primeiro plano parcelar da cidade, estabelecido em I830, era a reconstituição da geografia da cidade com base nas unidades parcelares construídas anteriormente por método regressivo. Isso implicava compreender a natureza espacial implícita das fontes

2 GAUTHIEZ, Bernard; ZELLER, Olivier. Lyon aux XVII-XVIIIe siècles, la fabrique de la ville. In: BAJOLET, E.; MATTEI, M.-F.; RENNES, J.-M. (Éd.) Quatre ans de recherche urbaine 200I-2004. Tours: Presses Universitaires François-Rabelais/Maison des Sciences de l'Homme, 2006, v. I, p. 459-463.

3 Archives Municipales de Lyon (AML), registros da série DD.

4 GAUTHIEZ, Bernard. Espace urbain, vocabulaire et morphologie. Paris: Editions du Patrimoine, 2003; GAUTHIEZ, Bernard. The history of urban morphology. Urban morphology, 8(2), 2004, p. 7I-89; GAUTHIEZ, Bernard. Des unités pertinentes pour mesurer la ville concrète. Histoire er mesure, XIX/3-4, 2004, p. 295-3I6. 
escritas seriais, em especial dos papéis fiscais e dos recenseamentos5. Essa dimensão do projeto foi um desafio, no sentido de que não existia nenhum plano vetor para o período anterior a I980, e porque as licenças de construção comportam apenas notações espaciais limitadas - uma rua, os vizinhos -, mas não os números na rua, que foram introduzidos em Lyon apenas em I790. A solução foi, por isso, construir um sistema de endereçamento fundado sobre a sucessão dos proprietários, reconstituída - parcialmente devido às lacunas das fontes - graças às fontes escritas sobre cada lote.

A extensão desse projeto ao período entre I763 e I900 tornou-se possível pelo exame minucioso dos arquivos das licenças de construção, que enriqueceram a base de dados com cerca de Io mil linhas ${ }^{6}$, e à reconstituição do sistema de numeração das ruas do período revolucionário, em atividade entre I790 até aproximadamente I8Io, quando se passou ao sistema pares-ímpares ainda em uso. Hoje, cerca de 2.280 (90\% de 2.535) das construções autorizadas antes de 1763 e 680 sobre-elevações do mesmo período ( $80 \%$ de 840 ) foram cartografadas com precisão. Para o período seguinte, todas as autorizações relativas ao perímetro da cidade existente em I8Io foram localizadas e incorporadas no SIG.

Para atingir esses resultados, foi necessário traçar os passos epistemológicos indispensáveis para desenvolver novos elementos do método em relação aos trabalhos mais antigos nesse domínio. Vários autores, na verdade, caminharam nessa direção, mas mantendo seus trabalhos "no papel" publicados em estudos temáticos. É fácil compreender que tal procedimento, que comporta qualquer fonte com elementos espacializáveis numa camada (layer) do SIG, permite uma capitalização extremamente fértil dos dados e permite abordar questões até agora desencorajadoras pelo investimento ex nihilo necessário.

Os acervos epistemológicos foram estendidos ao estudo das transformações da aglomeração de Lyon por Nicolas Ferrand ${ }^{8}$, na sua tese sobre as operações de urbanismo no território da Grande-Lyon entre I950 e 20I0, do mesmo modo os de Guillaume Sodezza ${ }^{9}$ sobre o vale do Gier e a transformação do seu espaço desde I80o. Também sob a minha direção, a tese em curso de Arnaud Bellec sobre a história da vegetação no espaço da Grande-Lyon se baseia nos trabalhos de Ferrand e enriquece, por sua vez, o SIG.

5 GAUTHIEZ, Bernard; ZELLER, Olivier. Ordre textuel et ordre spatial à Lyon à l'époque moderne. Du parcours de visite au rôle nominal, une spatialité implicite. Histoire er mesure XXV-I, 20Io, p. 197-230.

6 Os exames efetuados referem-se a todo o centro da cidade até I828, e parcialmente entre I828 e I900.

7 Boudon, Françoise et al. Système de l'architecture urbaine, le quartier des halles à Paris. Paris: Centre National de la Recherche Scientifique, I977; CLAVAL, Paul; CLAVAL, Françoise. Cahors au milieu du XVIIe siècle et la géographie sociale de la ville préindustrielle. In: CLAVAL, Paul. (Éd.). Géographie historique des villes d'Europe occidentale, II - Espaces sociaux et paysages urbains. Paris: Publications du Département de Géographie de l'Université de Paris-Sorbonne n. I4, I977, p. 69-72.

8 Ferrand, Nicolas. Approche morphologique de l'urbanisation: Lyon et son agglomération de 1945 à 2005, données, outils et méthode. Thèse (Doctorat de Géographie). Lyon: Université de Lyon Jean-Moulin, 2010.

9 Sodezza, Guillaume. Vers un atlas morphogénétique de la vallée du Giers. Caractérisation des éléments et structures matérielles hérités. Thèse (doctorat de géographie)., Lyon: Université de Lyon Jean-Moulin, 20I4. 


\section{CONSTRUIR O SIG}

\section{Base topográfica}

Para construir a base topográfica, foi seguido o seguinte método ${ }^{10}$ :

I) Primeira etapa - Estabelecer um plano vetor da cidade baseado no primeiro cadastro levantado em I830-I83I (I824 para a margem leste do Rhône), corrigindo a sua geometria de forma que os objetos figurem exatamente no mesmo lugar e de acordo com o mesmo contorno nas duas datas diferentes, tomando como referência de georreferenciamento o plano hoje utilizado para todos os trabalhos sobre o espaço da Grande-Lyon (chamado Système Urbain de Référence - SUR). O simples georreferenciamento das folhas do cadastro antigo e o rubber-sheathing não permitem essa correção e devem ser descartados. É necessário reinterpretar cada ponto e cada linha da fonte histórica, para, em certa medida, editá-los de maneira adequada. Três camadas (layers) principais foram desenhadas: lotes, construções, outros elementos topográficos (pontes, margens dos cursos de água, escadas etc.).

2) Segunda etapa - Com base nesse plano e usando em torno de 300 planos parciais do século XVIII representando construções e lotes ${ }^{\text {II }}$, como os planos de domínios senhoriais, foi estabelecido um plano vetor de Lyon para I745 sobre a mesma geometria de referência, também em três camadas principais ${ }^{\mathrm{I} 2}$.

\section{Sistema de endereçamento dos dados relativos às construções}

As fontes permitem, de maneira sistemática, para antes de I790, somente um sistema de endereçamento, referente à sucessão dos proprietários de uma mesma construção (as licenças de construção são dadas a um proprietário específico, as fontes fiscais e os recenseamentos referem-se sempre, ou quase sempre, ao proprietário do imóvel). Graças ao fato de Lyon ser, já no século XVI, uma cidade onde os imóveis eram plurifamiliares - o que não ocorria, de forma generalizada, à época moderna, na

Io Boudon, Françoise et al., op. cit.; SCHÄTTI, Nicolas; Viaccoz De Noyers, Anne-Marie. L'Atlas historique de la ville de Genève, vieilles méthodes, nouveaux outils. Patrimoine et architecture I4-I5, 2005, p. 58-64; GAUTHIEZ, Bernard. Lyon en I824-32: un plan de la ville sous forme vecteur d'après le cadastre ancien. Géocarrefour 83-I, 2008, p. 57-67; GREGORY, Ian N. A place in history: a guide to using GIS in historical research. Oxford and Oakville: Oxbow Books, 2003; GREGORY, Ian N.; ELL, Paul S. Historical GIS: techniques, methodologies and scholarship. Cambridge: Cambridge University Press, 2007.

II Por exemplo AML 2 S 26, Atlas de la rente noble de l'archevêché; Archives Départementales du Rhône (puis ADR) Io G 2338, capítulo de St-Jean; ADR I5 G I88, capítulo de St-Nizier etc.

I2 Esse plano primeiro foi desenhado manualmente nos anos I990. GAUTHIEZ, Bernard. Lyon, formation et évolution d'un espace urbain, I.- cartographie du site et Moyen-Âge. Vaulx-en-Velin: Ecole Nationale Supérieure d'Architecture de Lyon, I993. Ele foi vetorizado, e a sua geometria corrigida em 2005. 
maioria das outras grandes cidades da Europa -, o número de propriedades unitárias em determinado momento é limitado a aproximadamente $3.500^{\text {I3 }}$.

Dois métodos complementares foram seguidos para chegar a uma cartografia de endereçamento completa:

I) A partir do cadastro de I830-3I, onde consta o sistema de numeração par-ímpar estabelecido por volta de I8Io, foi possível cartografar os proprietários indicados no recenseamento de $I 8 I 4^{14}$. O primeiro recenseamento completo data de I808, mas é estabelecido de acordo com o sistema de numeração em uso desde 1790 . Como os proprietários são, em grande parte, os mesmos em I808 e I8I4, é possível cartografá-los em I808 mantendo os nomes onde são documentados nas duas datas, depois preenchendo as lacunas de I808, data na qual os imóveis estão dados de acordo com uma ordem contínua para cada bairro ${ }^{15}$.

2) A segunda fase foi a da utilização da ordem de listagem dos documentos mais antigos visando aos impostos e recenseamentos específicos para reconstituir a ordem espacial das propriedades nas ruas. Pode-se provar que a ordem de listagem foi bastante estável durante todo o século XVIII, e mesmo desde a metade do século XVII, somente com as pequenas modificações do caminho seguido pelos agentes administrativos responsáveis pela confecção das listas ${ }^{\mathrm{I}}$. Dessa forma, podemos cartografar a lista de

I3 Esse aspecto específico da tipologia dos imóveis de Lyon deve ser explicado. A habitação coletiva se desenvolveu a partir de I500, tornando-se completamente dominante por volta de I640. GAUTHIEZ, Bernard. Typologie architecturale et démographie. L'habitat collectif à Lyon à l'époque moderne, I500-I800. In: GRENET, Mathieu; JAMBON, Yannick; VILLE, Marie-Laure. (Dir.). Histoire urbaine et sciences sociales. Mélanges en l'honneur du professeur Olivier Zeller. Paris: Garnier, 20I4, p. I9-48. Isso implica que as unidades médias de financiamento imobiliário acompanharam um desenvolvimento capitalista, e que as condições de habitação e a tipologia dos imóveis foram adaptadas aos baixos salários da indústria da seda, principal atividade econômica da cidade e principal fonte da riqueza produzida. Essa riqueza era monopolizada por uma pequena parte da população, em especial os comerciantes-fabricantes. Os imóveis coletivos construídos a partir do início do século XVII contrastam com os imóveis mais antigos, que têm a forma de casas altas ou sobrelevadas, o que eram às vezes. Com o passar do tempo, a concentração da riqueza em Lyon foi crescente, até a Revolução (GARDEN, Maurice. Lyon et les Lyonnais au XVIIIe siècle. Paris: Les Belles Lettres, I970). Em consequência, o tamanho médio dos imóveis, correspondente às unidades médias de investimento crescente, aumentou, e o número médio de construções novas por ano diminuiu. A concentração da propriedade fundiária e da riqueza econômica era muito grande em I789. Para Paris, ver: CABESTAN, Jean-François. La naissance de l'immeuble d'appartements à Paris sous le règne de Louis XV. In: RABREAU, Daniel (Éd.). Paris, capitale des arts sous Louis XV. Bordeaux: William Blake and co/Arts and Arts, I997, p. I67-I95. Em consequência da dimensão crescente dos novos edifícios, com o número de andares passando de quatro, cinco ou seis, e o agrupamento de duas ou três casas preexistentes para poder construí-los, a superfície total construída em Lyon aumentou somente em torno de $30 \%$ entre I600 e I789, com um número de imóveis variando em torno de 3.400, ao mesmo tempo que a população mais que triplicava, passando de cerca de 40.000 habitantes para cerca de 150.000.

I4 AML 92I WP 023-025.

I5 AML 92I WP 005-0Io. O sistema numeração fixo estabelecido em I790 é uma evolução do anterior, mas com um número mais reduzido de bairros.

I6 GAUTHIEZ, Bernard; ZELLER, Olivier. Ordre textuel et ordre spatial à Lyon à l'époque moderne..., op. cit. 
impostos da vigésima $(\mathrm{I} / 20)^{17}$ de I789, relacionando-a ao recenseamento de I808, porque $30 \%$ dos proprietários são os mesmos, e os outros proprietários podem ser localizados graças à ordem da lista de 1789 . O resultado é confirmado pelos plans de censive $e^{18}$ contemporâneos, alguns dos quais indicam os proprietários.

E assim por diante. A lista de impostos da vigésima de 1766 foi cartografada facilmente em relação à de I789, utilizando o mesmo método. Para o período anterior, o exercício é mais delicado devido à falta de fontes seriais suficientemente próximas no tempo. Pude, contudo, localizar, com boa dose de certeza, os proprietários em I698 e I694, graças à lista de I766 e aos proprietários informados no Règlement Général d'Alignement de $1680^{\mathrm{Ig}}$, um texto que fornece, rua por rua, as linhas de fachada que devem ser respeitadas por toda nova construção e que menciona os proprietários dos imóveis de esquina, cerca de 800, ou seja, perto de um quarto do total ${ }^{20}$. A partir daí a cartografia dos dados, lamentavelmente parciais, de I677 é simples ${ }^{21}$.

Os mapeamentos dos proprietários, seguros para os anos I8I4, I808,I78922, I766 23 (a metade da cidade), I69824 e I677 (em parte)25, podem também ser feitos, mas sobre partes mais reduzidas ainda da cidade, devido às lacunas das fontes, para I744, I723, I636. Essa cartografia é, de fato, cada vez mais confrontada com os dados das licenças de construção. Eles se fortalecem mutuamente, até porque mais de $50 \%$ das licenças de construção se referem a imóveis contíguos em séries. Essas localizações também são confrontadas aos edifícios ainda existentes do período, ou seja, cerca de um terço

I7 O imposto de I/20 era anual e baseado na vigésima parte do valor de locação de uma propriedade, geralmente um único imóvel, mas às vezes também um grupo de imóveis ou uma parte, apenas. Como o valor de locação anual valia cerca de I/20 do valor fundiário de um edifício, o montante do imposto da vigésima valia cerca do I/400 do valor fundiário de um bem imobiliário. De fato, parece que o valor de venda de um imóvel era estabelecido partir do montante total dos aluguéis recebidos.

I8 Terra concedida mediante um cens anual (imposto) pago ao senhor. Bispos, cônegos, abades possuíam, dessa forma, feudos ou censives em virtude de suas funções eclesiásticas. Extraído de: TOCQUEVILLE, L’Ancien Régime et la Révolution,I856, p. 94, apud CNRTL - Centre National de Resources Textuelles et Lexicales. Disponível em: 〈http://www.cnrtl.fr/definition/censives >. Acesso em: 20 fev. 2016.

I9 AML DD 56.

20 O Consulat decide, em I698, estabelecer um sistema de iluminação pública nas ruas. Foi financiado com base numa taxa baseada no valor dos imóveis (AML FF 0754-0755). O Règlement Général d'Alignement foi adotado em dezembro de I680. Ele determinava para todas as ruas e todas as praças a linha que qualquer fachada de construção nova deveria respeitar. Seu objetivo era regularizar a largura das ruas nesse contexto de crescimento rápido do tráfego, e contribuir para o embelezamento da cidade.

2I O Consulat faliu em I677. Entre diversas medidas para restabelecer as finanças municipais, foi decidido impor um empréstimo a todos os ricos da cidade. Um inquérito foi feito com esse objetivo em cada bairro, do qual subsiste cerca da metade dos dados (AML CC 4I87). A cartografia da riqueza na cidade, apesar das lacunas, é muito interessante.

$22 \mathrm{AML}_{3} \mathrm{C}_{52}$.

23 AML 2 II I60.

24 AML FF 0754-0755.

25 AML CC 4187. 
da estrutura de Lyon em I789, que também são constituídos e documentados numa camada do $\mathrm{SIG}^{26}$. A iconografia, apesar da sua relativa escassez em Lyon, também é utilizada ${ }^{27}$. As iniciais dos proprietários, em geral colocadas acima das portas, no momento da construção, e o estilo arquitetural das construções constituem outros tantos elementos de concordância entre as fontes escritas, os imóveis existentes e a localização.

Cada fonte forma uma camada independente que pode ser comparada às outras para verificar os dados. Assim, anos de mapeamento e cruzamento das informações disponíveis permitiram estabelecer um sistema seguro de localização para o período posterior a I677, um pouco menos seguro para o período anterior, e a localização de quase todas as licenças de construção (figura I). A certeza é quase total para os setores centrais da cidade, os mais documentados, e onde numerosos imóveis da época moderna ainda existem. Os do século XIX impõem dificuldades apenas nos bairros novos, porque ali a numeração foi feita apenas após a urbanização. Contudo, pode-se utilizar as séries dos recenseamentos para reconstituir a ordem e a sequência ${ }^{28}$.

\footnotetext{
26 Numerosos imóveis ainda existentes levam as iniciais do proprietário no momento da sua construção, colocadas em letras de ferro forjado acima da porta principal. Algumas datas de construção são ainda legíveis sobre certos edifícios. Um estudo sistemático sobre o terreno foi feito para pôr em relevo esses dados.

27 Mas a iconografia tende a representar as mesmas localidades. Ela é mais rara em Lyon para o período moderno.

28 Os recenseamentos municipais são anuais de I8I4 até I847. Dispomos, depois, dos recenseamentos de Estado, a cada cinco anos em princípio, a partir de I836. Esses dados estão online nos sites dos Archives Municipales de Lyon e dos Archives du département du Rhône.
} 


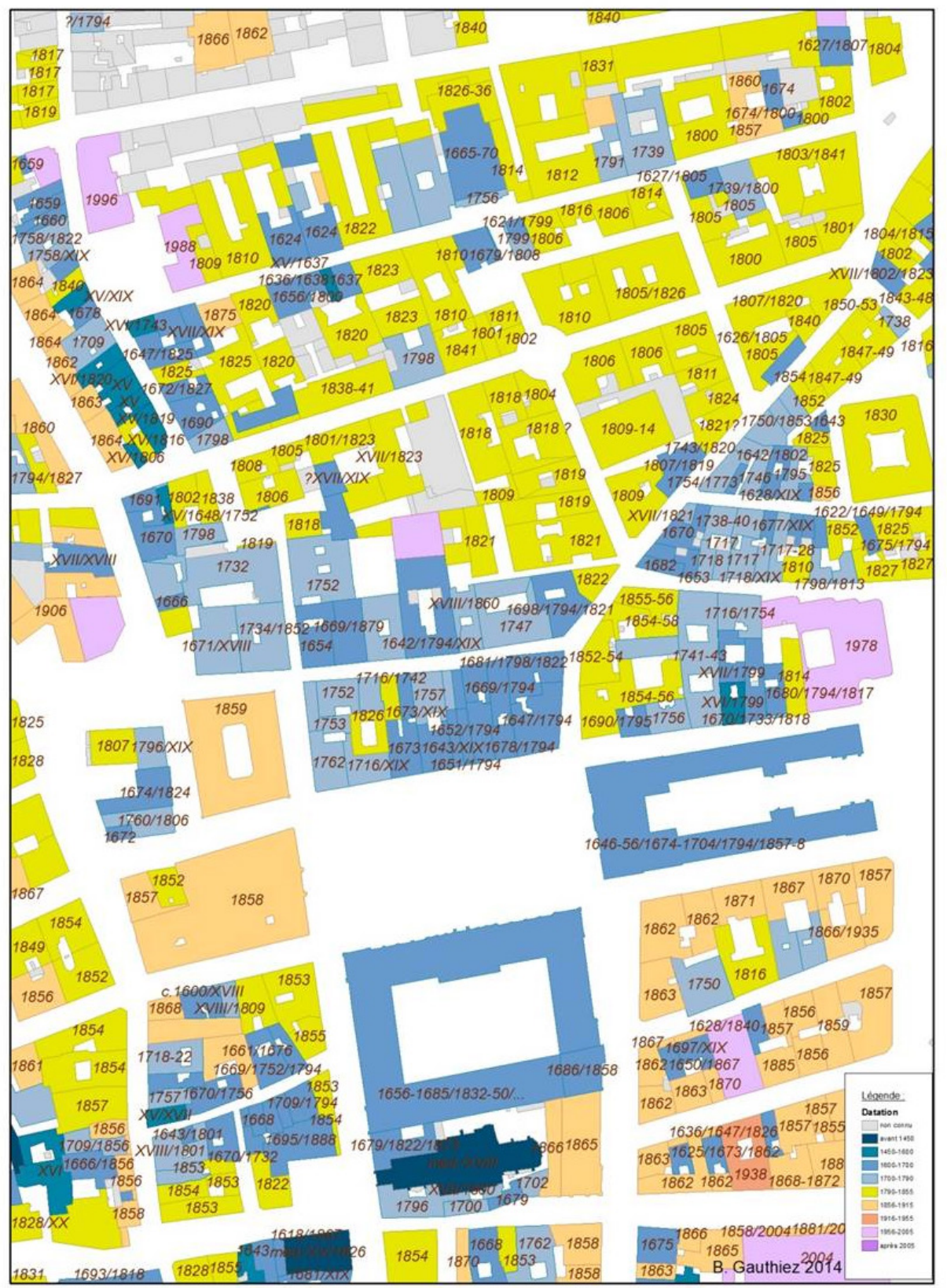

Figura I - Datação dos imóveis e de suas transformações a partir das licenças de construção, extrato do setor ao norte da praça des Terreaux (B. Gauthiez@20I6) 
A localização ao longo das ruas da periferia, onde a estrutura não era contínua ou as ruas eram particularmente compridas (rue de la Grande Côte, rue Pierre-Scize, com mais de um quilômetro), pode ainda apresentar algumas incertezas. A flexibilidade técnica do SIG permite elaborações prósperas em função de novas informações.

Parece que durante esses séculos a cidade foi administrada de forma muito regular. Todas as licenças de construção, com raras exceções, eram seguidas de construções, e os que tentavam escapar ao controle administrativo, ou ignoravam simplesmente sua necessidade, deviam pagar uma multa. Alguns eram obrigados a demolir a construção empreendida sem autorização, para retomá-la de acordo com as prescrições municipais, o que podia ser muito dispendioso. Pelo fato de a jurisdição sobre as licenças de construção e sobre as vias públicas não estar totalmente sob o controle do Consulat, certos setores da cidade não são bem conhecidos: o recinto canônico da catedral Saint Jean, os burgos de Saint Just e Saint Irénée, os subúrbios fora da cidade, que dependiam em parte da jurisdição real das Pontes e Calçadas, em parte dos domínios senhoriais, e as bordas das fortificações, dependentes da administração militar.

Uma vez esse trabalho feito, que foi possível graças à ajuda do meu colega historiador Olivier Zeller e de alguns estudantes, e do exame minucioso de numerosas fontes seriais dos arquivos municipais e departamentais de Lyon, cada uma constituída em camada no $\mathrm{SIG}^{29}$, uma nova história urbana, uma nova geografia histórica torna-se possível. Aqui estão alguns exemplos.

\section{OS CAMINHOS SEgUIDOS PELOS AGENTES ADMINISTRATIVOS PARA OS IMPOSTOS E OS RECENSEAMENTOS}

Esses caminhos revelam como o espaço era percorrido e a informação recolhida quando não se utilizavam plantas. Cada um dos 36 bairros da cidade (ou pennons) era percorrido de maneira diferente, de acordo com uma lógica geométrica própria, fazendo o tour des îlots, tentando percorrer a rota mais curta, ziguezagueando entre os imóveis dos dois lados de uma mesma rua...30 (figura 2). Isso implica que a administração de cada bairro tinha, em um momento dado (provavelmente por volta

29 Poderíamos pensar que o método mais simples seria fazer uma articulação entre uma camada de polígonos e uma base de dados, mas, pelo fato de as linhas da base de dados não corresponderem sistematicamente a um único imóvel, mas às vezes a um grupo ou a uma parte, cada linha deve ser reexaminada e os polígonos eventualmente reagrupados. Por exemplo, 3.82I entradas são listadas para o imposto da I/20 de I789, que correspondem a cerca de 3.43I edifícios (valor de I786 BRAC, F-P-S. Mémoire lu par M. Brac, avocat au parlement et aux cours de Lyon, ancien échevin de la même ville dans l'assemblée de Messieurs les anciens échevins de la ville de Lyon, tenue le mercredi 30 août I786 dans l'hôtel des exercices de la Flèche, avec quelques notes ajoutées par l'éditeur. Manuscrito, arquivos privados La Perrière, I787.

30 GAUTHIEZ, Bernard; ZELLER, Olivier. Ordre textuel et ordre spatial à Lyon à l'époque moderne.... op. cit. O número de bairros (ou pennons) variou ligeiramente no tempo, mas isso se refere apenas a algumas unidades da periferia. Os limites de cada bairro podiam também variar ligeiramente. 
de I540), determinado um percurso que foi repetido seguidamente, grosso modo, durante mais de dois séculos. Essa rota fixa levou à introdução de um sistema de numeração, a partir de I723, relacionado à ordem dos imóveis e não à posição deles. Assim, se o percurso fosse exatamente o mesmo em I766 e em I789, o número de um mesmo imóvel poderia deslocar-se na lista. A fixação espacial dos números em Lyon ocorreu apenas em I790 (figura 3). A compreensão dos modos de espacialização dos imóveis sem ter acesso à planta ajuda-nos, assim, a esclarecer uma parte da história da administração da cidade. $O$ modo de espacialização, antes da Revolução, era baseado essencialmente no conhecimento pessoal entre os responsáveis administrativos dos bairros e os 80 a 200 proprietários da sua circunscrição. Esse conhecimento pessoal era reforçado pela continuidade das fortunas no tempo, o que conduzia a associar um local a uma família, às vezes ela própria implicada na administração do bairro. Os percursos de visita começam, assim, frequentemente, pela casa do capitão do bairro.

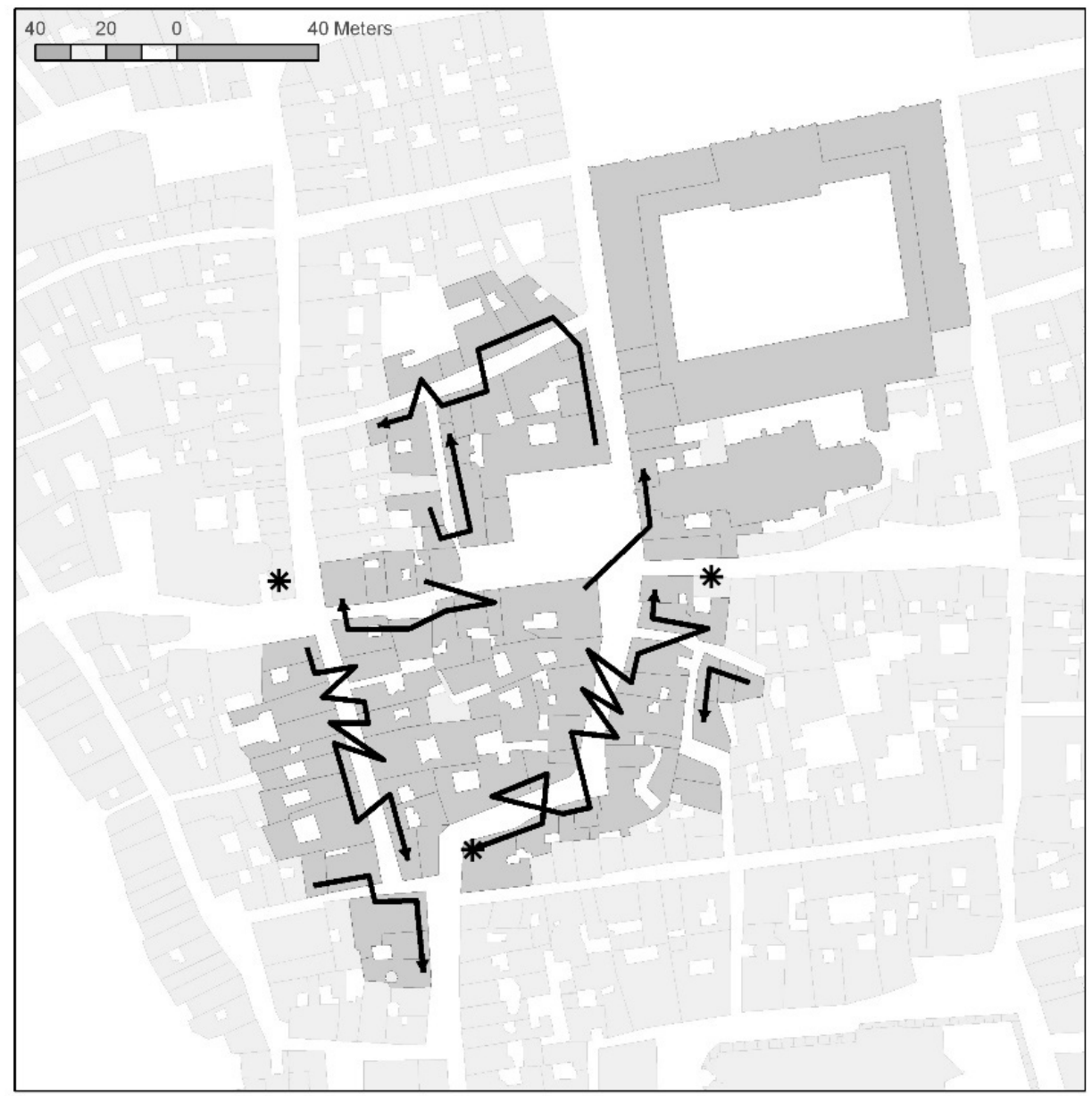

Figura 2 - Percurso do agente administrativo quando de um inquérito sobre a riqueza dos habitantes, Lyon, bairro de St.-Pierre, I677. Um caso de percurso complexo, baseado na passagem de imóvel a imóvel em ambos os lados de determinada rua (B. Gauthiez@20Io) 


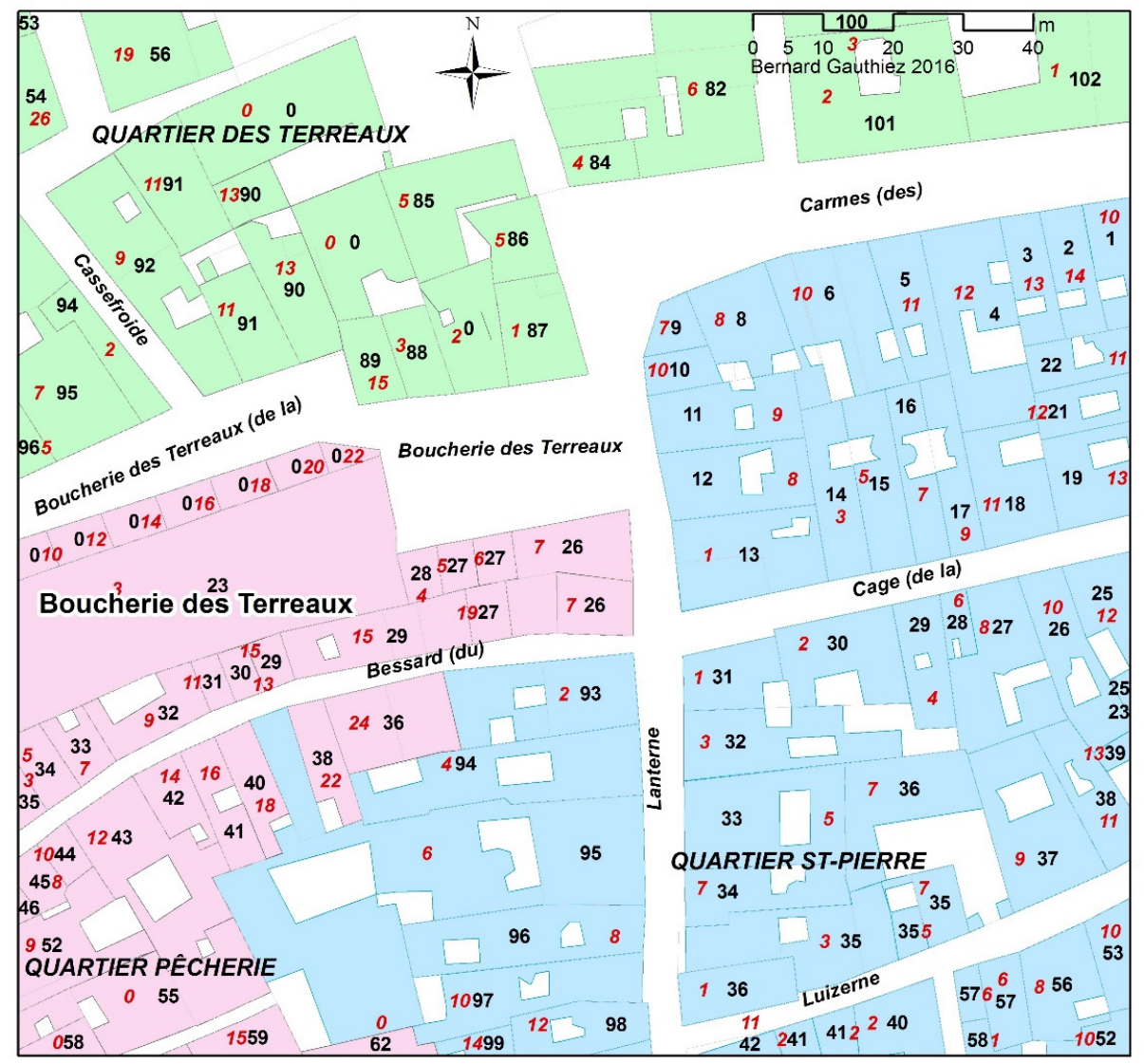

Figura 3 - Cartografia do sistema de numeração em I790 (números em série por bairro, em preto) e a partir de I8Io (números pares e ímpares para uma rua dada, em vermelho) (B. Gauthiez@20I6)

\section{A CARTOGRafia daS LiCENÇAS DE CONSTRUÇÃo}

Como a cartografia foi feita de acordo com objetos que são o resultado de processos sociais documentados ${ }^{31}$, isso permite reconstruir o filme da transformação da cidade material e questionar as lógicas em jogo - localização, meio social e usos - quando dispomos de dados econômicos. O filme do investimento imobiliário faz surgir períodos e espaços de intensidade variável, elevada ou fraca. Faz também aparecer efeitos de escala até agora não identificados, em especial o modo segundo o qual construções novas formam, muito frequentemente, uma cadeia. Quando um imóvel era reconstruído, os imóveis vizinhos, muitas vezes, o eram também ou, mais frequentemente ainda, eram simplesmente reabilitados nos anos seguintes.

3I GAUTHIEZ, Bernard. Des unités pertinentes..., op. cit. 
O Consulat incentivava esse processo, sobretudo proibindo de reparar os ângulos das fachadas dos imóveis não recuados, ao mesmo tempo que permitia alargar e embelezar trechos de ruas. Esse processo envolve provavelmente mais de $50 \%$ das novas construções.

Outro efeito das reconstruções se torna evidente pela cartografia do alargamento das ruas, devido ao recuo das novas fachadas em comparação às antigas, então substituídas. Esse recuo media de 30 centímetros a quase seis metros (I a 20 pés). A política da administração do Consulat foi constante e muito eficaz. Certamente, o recuo foi limitado aos séculos XVII-XVIII, mas era já uma melhoria considerável se levarmos em conta a largura das ruas antigas, em torno de Io pés para muitas delas $(3,5 \mathrm{~m})$, um pouco mais de I5 para as mais importantes $(5,5 \mathrm{~m})$. Essa política respondia ao crescimento do tráfego de veículos, carroças e carros, e visava reduzir os engarrafamentos frequentes nos cruzamentos importantes. O período mais ativo dos alargamentos, dos quais os primeiros datam, o mais tardar, do fim do século XVI, começou nos anos I660. Essa mudança significa provavelmente uma evolução importante nas modalidades de transporte de mercadorias e dos membros da elite. Os carros e carroças multiplicaram-se, substituindo cavalos e mulas. Trata-se, também provavelmente, de um passo essencial para a Revolução Industrial, quando a indústria da seda estava em pleno desenvolvimento.

Esse movimento se tornou perceptível apenas pela cartografia sistemática. A sua progressividade e a ausência de dados sobre a circulação impediam de identificá-lo (figura 4). Neste sentido, e por esse exemplo, a cartografia das licenças de construção é indispensável para compreender a extensão e os objetivos da política de ordenamento urbano do município ${ }^{32}$.

32 GAUTHIEZ, Bernard; ZELLER, Olivier. Le dédommagement des reculements: un instrument de la politique d'aménagement urbain à Lyon aux XVIIe et XVIIIe siècles. Histoire er mesure, XXVIII-I, 20I3 p. 45-73. 


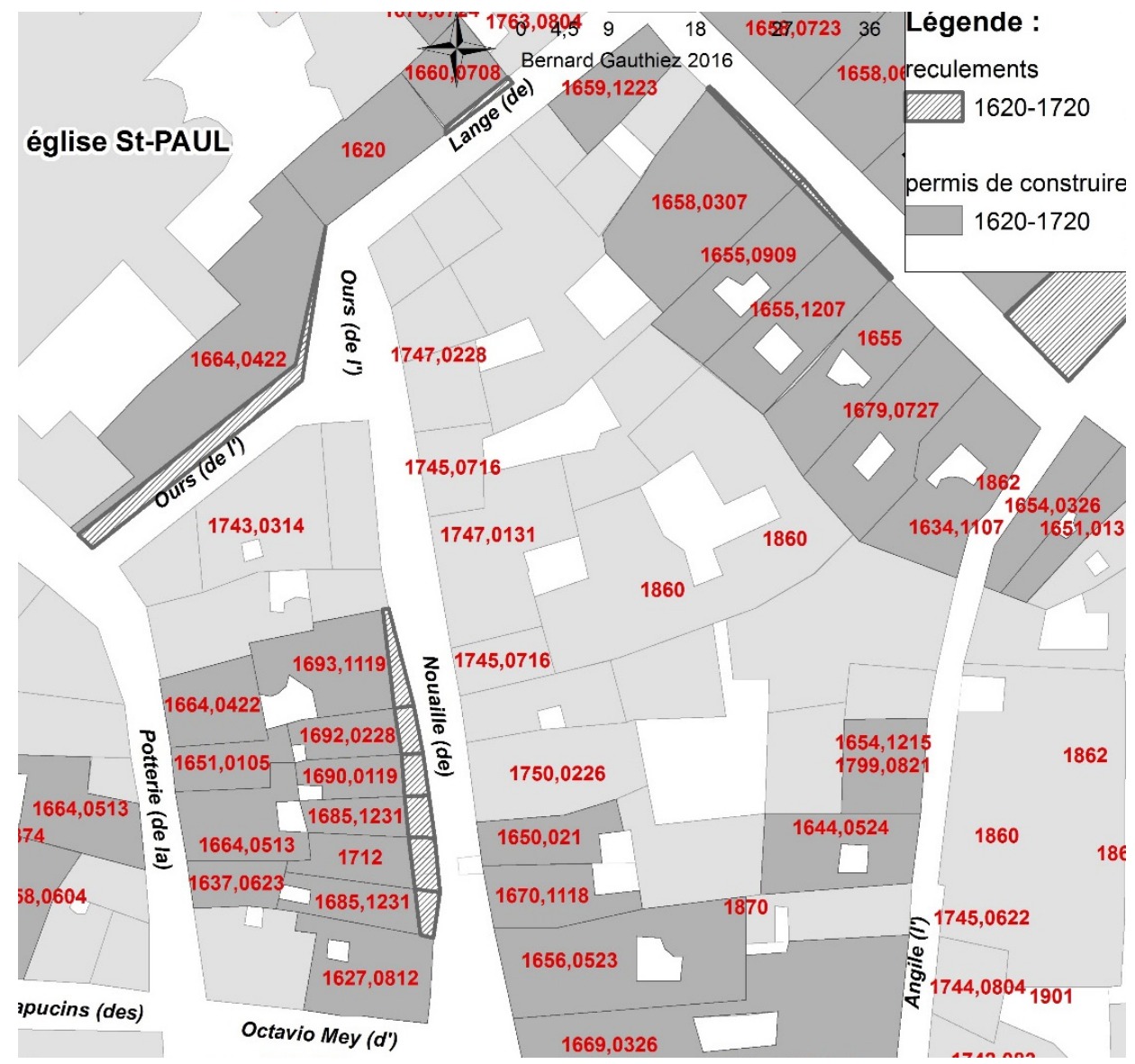

Figura 4-Exemplo de ruas alargadas entre I620 e I720 no bairro a sudeste da igreja de St.-Paul, mostrando a política de alargamento das ruas principais (B. Gauthiez@20I6)

\section{A localização doS TEARES E dOS TRABalHadoreS DA INDÚSTRIA DA SEDA EM I62I, I744 E 1833}

A partir do século XVII, Lyon desenvolveu-se como uma grande cidade industrial, com sua economia fundada sobre a tecelagem da seda. Conheceu vários movimentos sociais importantes, em especial a revolta de $1744^{33}$. Essa revolta conduziu a várias decisões de natureza principalmente política. Os distritos policiais foram reorganizados e reconstituídos em I74634; o Consulat foi também reorganizado; um

33 ZELLER, Olivier. Géographie des troubles et découpage urbain à Lyon (XVIème-XVIIIème siècles). In: CONGRÈS DES SOCIÉTÉS SAVANTES, II4. Paris, I989. Les espaces révolutionnaires. Paris: Editions du Comité des Travaux Historiques et Scientifiques, I990, p. 43-59.

34 AML EE II, AML 3 S 693. 
registro dos mestres e trabalhadores da seda (a "Grande fabrique") foi estabelecido eficazmente em I $745^{35}$. Seu principal objetivo era um melhor controle dessa população um tanto renitente, objetivo apenas em parte atingido, pois os movimentos de expressão do descontentamento dos trabalhadores não cessaram de fato, permanecendo durante algumas décadas mesmo com amplitude menor.

A cartografia dos mestres da seda, efetuada a partir do registro iniciado em I745, nos dá uma clara compreensão do espaço da seda na cidade (figura 5). 0 mapa é impressionante sob dois aspectos: os mestres (os trabalhadores em geral eram alojados junto ao seu mestre) habitavam geralmente a periferia do centro da cidade. Um mesmo espaço, de uma ou duas peças, abrigava os teares, a família do mestre, e o alojamento, os seus empregados solteiros, homens e mulheres. Nos bairros muito centrais e nos setores aristocráticos, como os arredores da praça Bellecour, não se encontrava nem mestres da seda, nem teares, obviamente. Eles estavam concentrados nos bairros mais pobres da cidade, constituindo, eles mesmos, a maior parte dessa pobreza. A partir do primeiro mapa elaborado com os dados de I62I, a fabricação dos tecidos de seda aparece claramente localizada nos espaços da periferia do centro, simultaneamente ao norte, a leste e ao sul. Os dados de I677, provenientes de um inquérito sobre a riqueza dos habitantes da cidade, com o propósito de um empréstimo forçado, dão indicações sobre a extensão progressiva da indústria da seda a partir do centro. A tendência é claramente visível depois de I745, a partir de informações do recenseamento de I833, que permitem cartografar o número de teares por imóvel. Trata-se de uma tendência de longa duração que constatamos por, pelo menos, mais de dois séculos desde I622. Em outra escala, a cartografia também enfatiza a tendência à concentração dos mestres e dos teares em certos imóveis. Essa especialização é estreitamente ligada às licenças de construção, o que denota a sobreposição dos mapas dos mestres e das autorizações. Isso significa que certos imóveis eram financiados e construídos precisamente para abrigar e alojar os mestres da seda. Esse fenômeno, importante para compreender a arquitetura da cidade, não poderia ser, nas pesquisas atuais, informado de outra forma a não ser por essa cartografia, porque os imóveis da indústria da seda não se distinguem tipologicamente dos outros. O processo de financiamento e de investimento imobiliário subjacente e seus agentes envolvidos, agentes privados e instituições como o Hôtel-Dieu necessitam ser estudados de maneira mais exaustiva. Na historiografia lionesa, cada mestre da seda deveria trabalhar independentemente, possuindo os próprios teares que operava no seu apartamento. É evidente, agora, que o agrupamento dos mestres poderia ser, em parte, organizado e que certos edifícios funcionavam, de fato, praticamente como manufaturas, ainda que os seus ocupantes não fossem assalariados, sendo pagos por tarefa, mesmo se fossem, em princípio, artesãos livres. Esse outro processo está também aberto à investigação, em especial do ponto de vista dos que trabalhavam para os mestres referidos em cada imóvel.

35 AML HH 578. O registro já era previsto anteriormente, mas pouco considerado. 


\section{L'espace de la soierie: 1621 / 1744 / 1833}

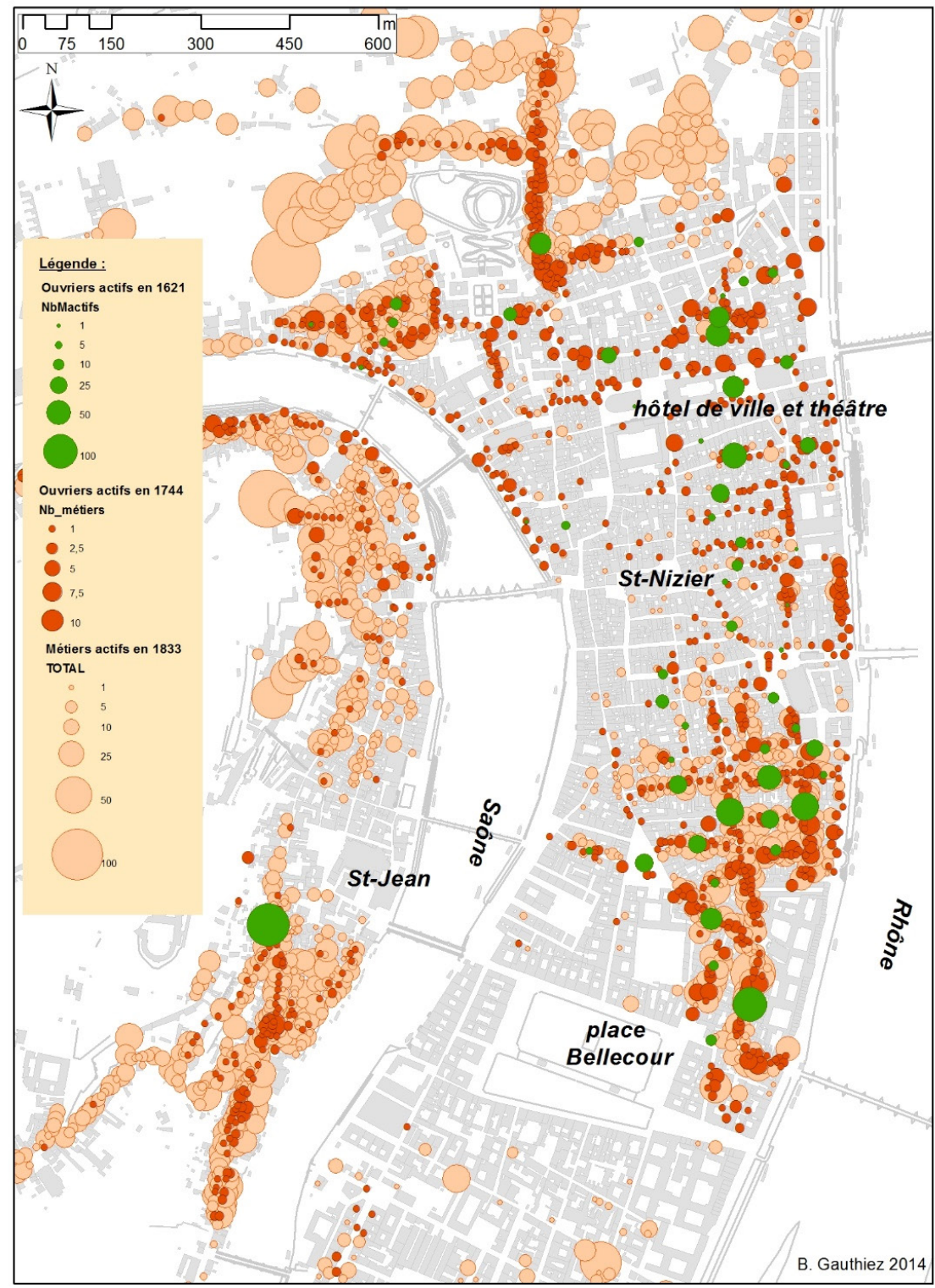

Figura 5-O espaço da indústria da seda: I62I; I744; I833. Cartografia dos chefes de ateliê da indústria da seda em I62I - em verde (por rua, ateliês); em I744 - em vermelho; em I833 - em rosa (por imóvel, ateliês e depois teares), em Lyon. A diacronia mostra as lógicas de desenvolvimento e deslocamento espacial da atividade, na medida do crescimento da cidade. O mapa mostra particularmente o forte crescimento verificado entre I8I5-I833 (B. Gauthiez@20I6) 
Esse processo é particularmente perceptível nos recenseamentos, por exemplo no de I833, que menciona o número de teares por ateliê/habitação de mestre ${ }^{36}$. Essa informação era muito útil para a polícia porque outra revolta operária aconteceu em I83I, como em I744 (uma das duas famosas revoltas dos canuts, nome que começou a ser dado aos trabalhadores da indústria da seda nos anos I830). Outra revolta, mais mortífera, aconteceu no ano seguinte, em I834. O centro da cidade foi, nessas ocasiões, controlado pelos trabalhadores. Nas duas circunstâncias, a administração reagiu, com 90 anos de intervalo, de maneira similar. Esses recenseamentos nos dão uma informação espacial anteriormente desconhecida, que podemos cruzar com o mapa da revolta de I834, elaborado pela administração militar (figura 6).

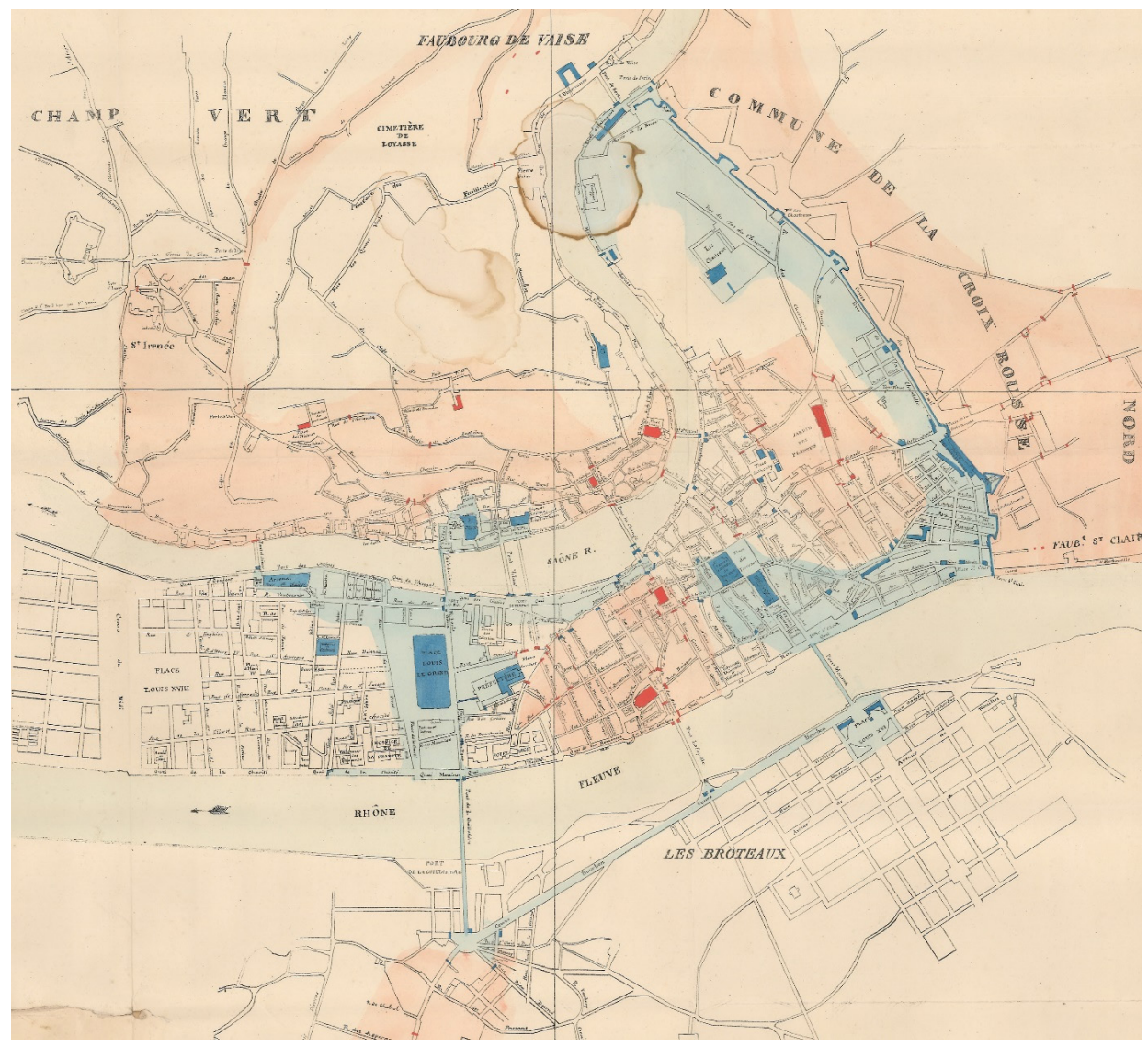

Figura 6 - Mapa da revolta de I834, estabelecido pela administração militar.

Em vermelho, os trabalhadores insurrectos; em azul, as forças de ordem e o exército (Archives de l’Institut Géographique National, St.-Mandé)

36 AML 92I WP I5I-I58. 
Entre I745 e I833, e sobretudo depois de I8Io, a indústria da seda tinha se estendido consideravelmente pela cidade, seguindo direções já perceptíveis em I745: nos antigos bairros lineares da margem direita do Saône, rua Saint-Georges e rua de Pierre-Scize, ao longo da rua de la Grand'Cotê de maneira similar para o norte e ao redor do hospital do Hôtel-Dieu. Outras áreas novas também surgiram, ao norte, em loteamentos de terrenos de instituições religiosas que foram suprimidas durante a Revolução, como os dos oratorianos e das carmelitas em I820, onde a maior concentração de teares estava presente em I833. O mesmo processo estava em andamento nos capuchinhos, acima do bairro de Saint-Paul. Desse lado da cidade, sobre a encosta do Fourvière, numerosos imóveis anteriormente ocupados por pessoas ricas, comerciantes e banqueiros, agora eram habitados por pobres que teciam a seda. O equilíbrio entre as duas margens do Saône era assim transformado: a margem direita pauperizando-se consideravelmente, e a margem esquerda, entre o Saône e o Rhône, se enriquecendo. A tendência a produzir imóveis adaptados aos ateliês dos tecelões da seda é bastante forte em I833, nos novos loteamentos então povoados por esses trabalhadores. $\mathrm{O}$ loteamento da rua Pierre-Blanc, no terreno das carmelitas foi, assim, dedicado especificamente a esses trabalhadores e às suas habitações/ateliês. Todos os imóveis ali erigidos entre I822 e I827 foram, desde a sua conclusão, assim ocupados. Num dentre eles, contamos I39 teares, um pouco menos que no vizinho "imóvel de 400 janelas", o maior imóvel da cidade dedicado à indústria da seda, onde havia I58 teares. Esses são, com o antigo convento dos capuchinhos, da subida dos Carmes-Déchaussés (II9 teares), os três imóveis que abrigavam o maior número de teares. Nessa época, a expressão caserne ouvrière era, às vezes, utilizada para designar essas construções que podiam se parecer com fábricas. $\mathrm{O}$ agrupamento espacial dos trabalhadores da seda estava assim parcialmente organizado e, pelos aluguéis recebidos, era muito vantajoso aos proprietários dos imóveis (embora o investimento imobiliário não fosse propriamente para obter lucros com o comércio dos tecidos de seda). O discurso oficial designando os trabalhadores da seda como artesãos livres e o folclore desde então construído sobre essa ideia, e embelezando suas vidas, através de Guignol, um personagem cômico, herói canut do teatro de marionetes, podem parecer, hoje, um tanto cínicos. A revolta de I834 teve uma conotação mais política; a cidade foi, de novo, ocupada pelos trabalhadores. Cerca de I.ooo vítimas pereceram quando da retomada de Lyon pelas tropas governamentais, tanto operários como soldados.

O desenvolvimento industrial, além dos bairros centrais pobres, era principalmente um fenômeno de franja urbana, nalguns casos antiga e englobada numa nova auréola de crescimento. A periferia, contudo, tinha se tornado, em certos setores, o lugar de residência de categorias sociais muito abastadas: no bairro Saint-Clair, à beira do Rhône, a nordeste do centro da cidade, e no bairro de Ainay, ao redor da praça Bellecour, ao sul. 


\section{UM EXEMPLO DE TRATAMENTO COMPLEXO DOS DADOS: $O$ VALOR FUNDIÁRIO DOS IMÓVEIS EM I698, I766 E I840}

O valor fundiário é extremamente rico de informações sobre a relação entre o espaço construído e o espaço social, ainda mais porque podemos associá-lo com a idade dos imóveis e sua localização precisa, que reflete as polaridades econômicas e/ou sociais. Sua cartografia é, assim, um grande avanço no nosso conhecimento da história social e espacial da cidade. Para atingir este objetivo, o seguinte método foi seguido:

I) Primo - Cartografar a estrutura em uma data que corresponde a uma fonte de dados fiscais disponíveis. Essa cartografia foi descrita na primeira parte deste artigo. Aqui, utilizei I698.

2) Secondo - Calcular o valor dos imóveis a partir da fonte. É muito fácil, na medida em que as fontes utilizadas consistem principalmente em impostos, dos quais o montante é derivado do valor do aluguel das propriedades. Isso significa, na realidade, o cálculo da renda anual percebida pelo proprietário da parte de seus inquilinos, depois o cálculo do imposto como uma proporção dessa renda.

Vimos como se calculava o imposto denominado vigésima. Em I698, a taxa para o estabelecimento das lanternas era de um milésimo do valor total dos imóveis. Em I840, o recenseamento municipal informa, para cada habitação e atividade, o valor do aluguel, que podemos então somar para determinado imóvel, o que representa cerca de I/20 do valor fundiário. Dessa maneira, o valor de cada propriedade pode ser estabelecido, sobre uma base comum, a partir do valor do aluguel em I698, I766 e I840, ou seja, em datas separadas de 68 e 74 anos. As nossas pesquisas nos arquivos não forneceram outra fonte fiscal antes de I808, exceto em I694, que é muito próxima de 1698 .

3)Tertio - Trata-se agora de calcular a área dos imóveis. Essa tarefa implica mais incertezas e dificuldades. A área total dos imóveis é calculável no SIG para I830, data do primeiro plano cadastral, o qual vimos que foi vetorizado. Dispomos, também, para os períodos anteriores, com base nas construções existentes e atestadas por planos mais antigos, sempre os cruzando com as datas de construção. Uma verificação é feita, sobre essa base, da existência de uma construção na data de um imposto. Conhecemos quase todos os imóveis para 1840, descritos no recenseamento do mesmo ano e presentes no cadastro de I830, com algumas exceções ${ }^{37}$. Quando recuamos no tempo, o número de imóveis para os quais a informação sobre a área total é conhecida diminui devido às reconstruções relativas a imóveis que, uma vez destruídos, não são mais documentados. O valor fundiário foi calculado como um valor do metro quadrado de área. Efetivamente, o número de andares varia consideravelmente, entre dois e seis, além do térreo. Os andares de subsolo foram excluídos, porque não foram informados. O número de andares pode ser inferido dos dados dos recenseamentos a partir de I808, e de alguns planos parciais do século XVIII,

37 Os sótãos, desde I750, foram utilizados cada vez mais frequentemente como habitação, com a adição de claraboias. Os telhados de baixa inclinação tornavam seu uso muito difícil, o que explica que seus ocupantes eram muito pobres, as viúvas e as jovens mulheres em particular. 
que foram mencionados. As autorizações de sobre-elevação, sobre um ou dois andares, também foram levadas em conta. A incerteza do resultado deve-se à imprecisão sobre a altura dos edifícios (por exemplo, no caso de andares debaixo do sótão), à extensão exata das construções no solo, ao fato de algumas de suas partes poderem ter alturas diferentes e ao fato de que se adicionam totais por níveis, sem retirar as partes não úteis, como os muros ou as escadas. Além disso, as construções representadas em I830 foram, às vezes, ampliadas ligeiramente após a sua construção.

O valor cartografado é o valor fundiário total dividido pela soma das superfícies de cada nível. O mapa exprime claramente diferenças entre imóveis vizinhos, e faz aparecer lógicas muito fortes de polarização que variam com o tempo em quase I50 anos. Para tornar a comparação significativa, a unidade de valor de referência escolhida é a da libra em I766, com base na qual os valores de I698 e I840 foram recalculados para evitar os vieses devidos à inflação.

\section{Livres valeur 1766 par M2}

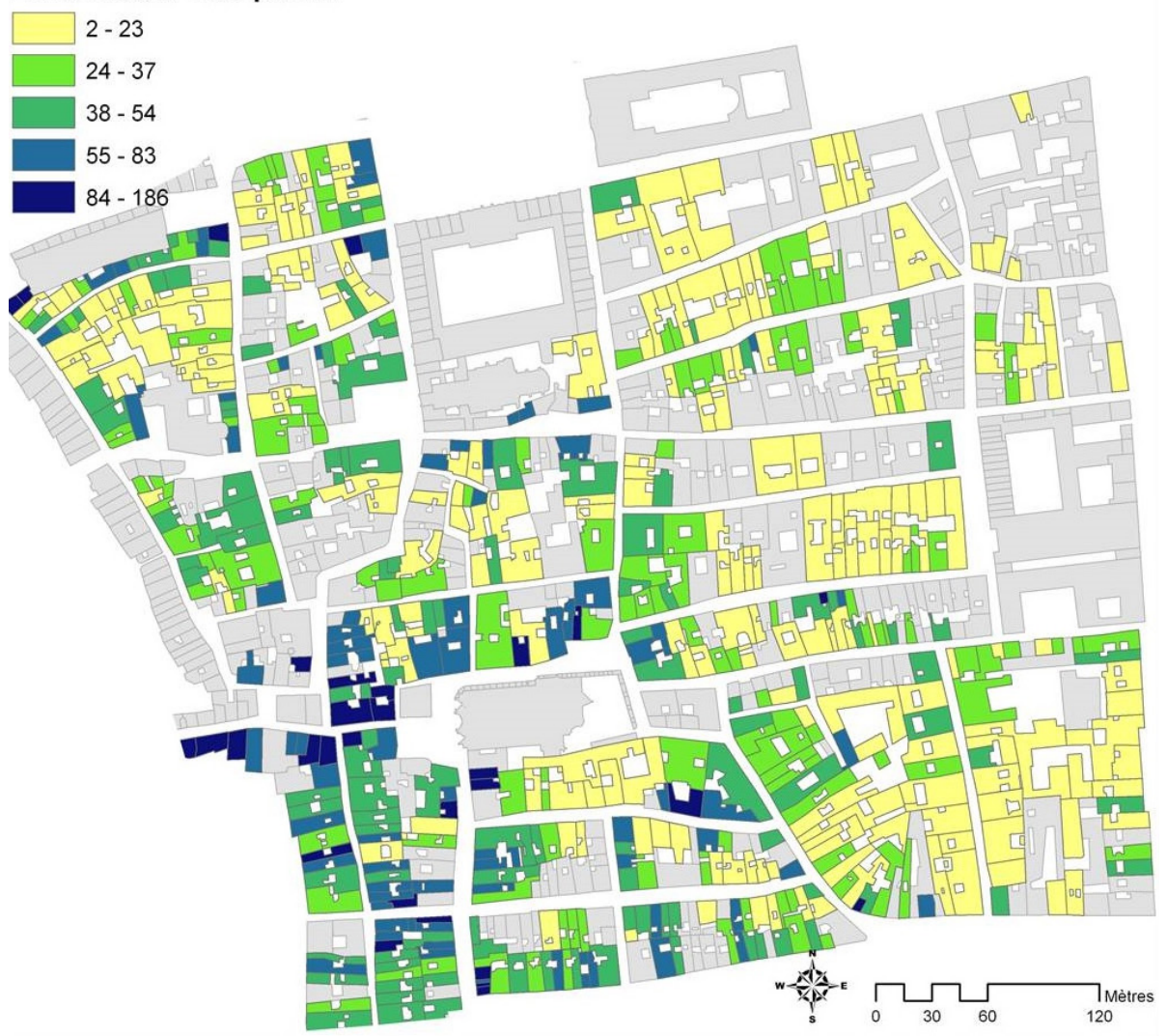

Figura 7-Valores fundiários em libras, de I766, por $\mathrm{m}^{2}$, no centro de Lyon, em I698. A área dos imóveis em cinza não é conhecida (B. Gauthiez@20I3) 
O mapa dos valores fundiários em I698 (figura 7) na zona central da cidade, a leste do rio Saône, nos mostra uma nítida polarização dos valores mais elevados em redor da extremidade leste da ponte do Saône, uma situação antiga, pelo fato de essa ponte ter sido, por muito tempo, o único ponto de travessia do rio. A rua Mercière concentra também valores elevados. Ela conduzia à única ponte sobre o rio Rhône. A grande diferença entre os valores mais baixos e os mais elevados, com uma diferença em torno de 4, a menos de $200 \mathrm{~m}$ de distância, é muito impressionante. Os valores de I766 (figura 8) reproduzem a mesma configuração, mas uma nova zona de valores elevados aparece entre a igreja St.-Nizier e a Prefeitura Municipal, num setor central, ao longo da rua Clermont, em particular. Ela é associada claramente numerosas reconstruções no bairro, de acordo com uma tipologia de imóveis coletivos novos, e acompanhados sistematicamente do recuo das fachadas para alargar as ruas, num processo de gentrificação.

\section{Livres valeur 1766}

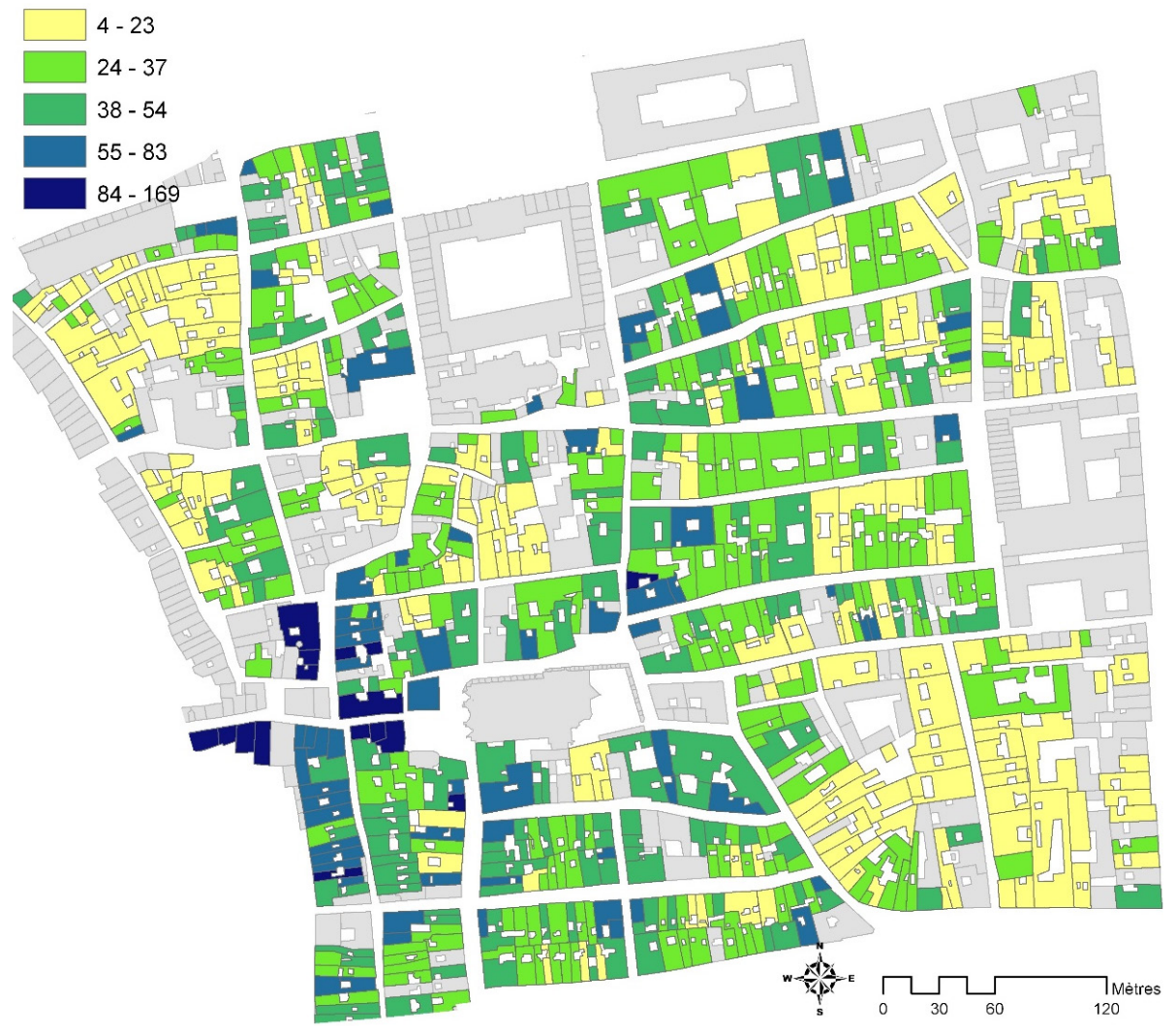

Figura 8 - Valores fundiários em libras, de $\mathrm{I} 766$, por $\mathrm{m}^{2}$, no centro de Lyon, em I766. A área dos imóveis em cinza não é conhecida (B. Gauthiez@20I3) 
Valores muito elevados estão também presentes onde as ruas foram alargadas e, por conseguinte, nos imóveis reconstruídos, particularmente em redor da saída da ponte do Saône e ao longo das ruas leste-oeste entre a rua Clermont e o Rhône, a leste (rues Mulet, du Bat-d'Argent, de l'Arbre-Sec, Pizay). O mapa dos valores em I940 (figura 9) aponta uma importante evolução, ainda que a estrutura tenha sido pouco renovada desde I766. Os valores médios são mais difusos, mas os mais elevados agora são muito concentrados ao longo de algumas ruas principais, uma que liga a praça des Terreaux, em frente à Prefeitura Municipal, e a ponte sobre o Saône e depois para o sul, no novo cais aberto em I7I9; a outra, a rua Clermont, em grande parte reconstruída já anteriormente. O setor da rua Grenette, um tradicional centro do comércio da cidade, perdeu parte do seu valor, o que significa parte da sua importância econômica. A importância do tráfego nas ruas principais, facilitado pelas reconstruções em recuo para alargar as ruas, foi um fator essencial na elevação dos valores fundiários. Contudo, somente algumas ruas concentram fortemente esse valor.

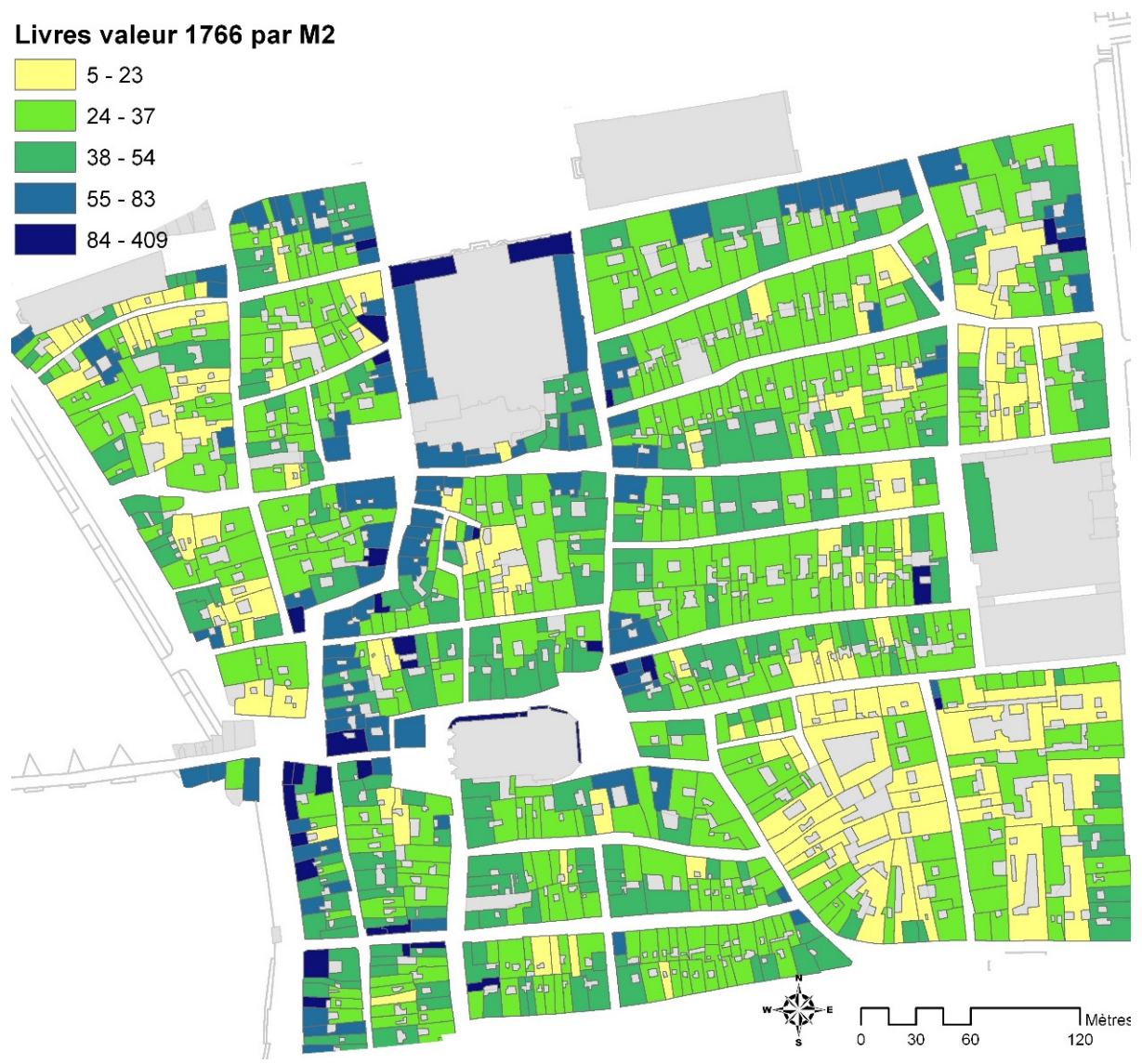

Figura 9-Valores fundiários em libras, de 1766 , por $\mathrm{m}^{2}$ de área, no centro de Lyon, em I840 (B. Gauthiez@20I3) 
Um mapa feito a partir das diferenças dos valores em habitações e em atividades, por imóvel, mostra bem os polos da economia do bairro (figura Io). É necessário ter cuidado quanto ao significado social desses valores, tomados como um todo para cada imóvel. Com efeito, somente a fonte de I840 permite fazer a distinção entre os valores relativos às habitações e aqueles que correspondem às atividades econômicas. Na verdade, os valores mais altos dos imóveis para as habitações não se sobrepõem exatamente aos valores mais altos calculados somente para as atividades. Consequentemente, esses mapas mostram sobretudo a concentração dos valores mais altos das atividades econômicas, em especial o comércio de luxo, os ateliês, as lojas.

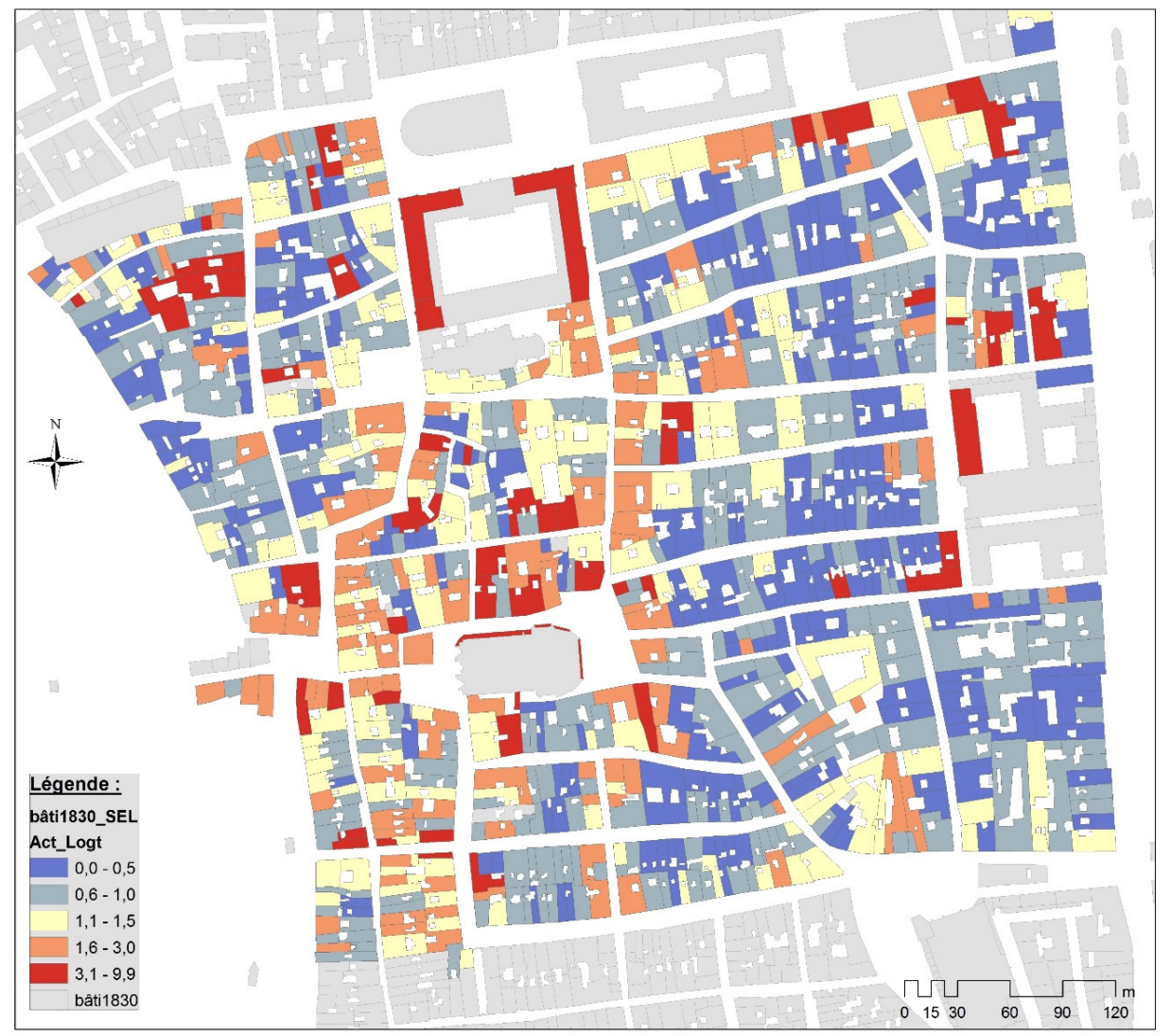

Figura Io - Relação entre valor fundiário das atividades e valor fundiário das habitações em I840, mostrando, em cores quentes, a forte polarização econômica (B. Gauthiez@20I6)

O recenseamento de 1840 e as licenças de construção mostram que os novos imóveis entre a Prefeitura Municipal e a igreja de St.-Nizier eram habitados, pincipalmente, por famílias da classe mais abastada, em grandes apartamentos com 
aluguéis mais altos, mas com o valor do metro quadrado mais baixo que nas zonas mais valorizadas, em média.

\section{Conclusão}

A possibilidade de localizar, na escala do imóvel, os valores de locação dos apartamentos e das atividades econômicas e, dessa forma, a utilização dos espaços abre vastas perspectivas de pesquisa. Sem essa precisão, a geografia social dos trabalhos históricos sobre as cidades permaneceria bastante sumária, encerrada em dados impossíveis de desconstruir. Podemos cartografar os dados à escala das paróquias e dos bairros, segundo as fontes ${ }^{38}$. Evidentemente, as seções administrativas são, às vezes, suficientemente pequenas para constituir unidades bastante homogêneas socialmente, principalmente quando a segregação espacial era eficaz e o hábitat monofamilial. Mas esses casos não são muito frequentes, e a heterogeneidade do uso dos espaços urbanos é forte, se seguirmos as fontes escritas disponíveis. O significado econômico e social dos bairros tornou-se um postulado, uma hipótese que foi desqualificada por Cabantous ${ }^{39}$. A cartografia à escala dos imóveis, aplicada ao SIG, permite agora determinar uma boa escala de estudo para uma questão dada.

É possível ir além. Realmente, em certos contextos das fontes escritas, é possível descer à escala dos apartamentos nos imóveis multifamiliares e/ou multiatividades, em três dimensões, conforme a localização em tal ou tal andar ${ }^{40}$. Os recenseamentos do século XIX permitem isso, mas a documentação arquitetural, que ainda está muito dispersa, permitiria apenas estudos para alguns imóveis. Isso nos ajudaria consideravelmente na compreensão da segregação e da divisão por tipo. Os inquéritos administrativos da época moderna, como o recenseamento de I709, sugerem, pela lógica das listas de famílias por imóveis - que parecem corresponder muito sistematicamente com a sucessão vertical dos andares, do mais baixo ao mais alto -, uma forte divisão entre uma "cidade masculina", no nível das lojas e dos ateliês, e uma "cidade feminina" nos andares mais altos. Certos imóveis em I677 eram habitados unicamente por mulheres, em alguns casos com um só homem no térreo, cujo papel pode ser suposto, talvez uma forma de proteção, ou de controle.

Tais estudos sobre os imóveis não esclarecem, contudo, o que se passa nos espaços

38 MICHEL, Henri. Urbanisme et société à Montpellier sous l'Ancien régime. Un exemple: le sixain Saint-Firmin (I665-I756). Annales du Midi, II6, I974, p. 2I-43; PASCAL, C. Bipolarisation sociale dans la ville d'Ancien Régime. Le sixain Sainte-Croix de Montpellier, I665-I788. Revue d'Histoire moderne et contemporaine, 4I-43, I994, p. 395-4I7; JUNOT, Yves. Mixité sociale, habitat et propriété: la paroisse Saint-Jacques de Valenciennes en I602 d'après un registre du centième. Revue du Nord, LXXIX, I997, p. 4I3-427; CABANTOUS, Alain. Le quartier, espace vécu à l'espace moderne. Histoire, economie et société, 3, I994, p. 427-440; etc.

39 CABANTOUS, Alain. Histoire de la nuit. Paris: Publications de la Sorbonne, 2008.

40 ZELLER, Olivier. Espace privé, espace public et cohabitation. Lyon à l'époque moderne. In: HAUMONT, Bernard; Morel, A. (Éd.). La société des voisins, partager un habitat collectif. Paris: Editions de la Maison des Sciences de l'Homme, 2005, p. I87-207. 
públicos e não construídos. Para estes, outros métodos devem ser seguidos, por uma cartografia de natureza diferente ${ }^{4 \mathrm{~T}}$. Mas o SIG permite também seguir o percurso da habitação das pessoas graças às localizações sucessivas dos seus apartamentos. Do mesmo modo, pode-se abordar a questão da relação entre o lugar de residência dos proprietários e o de suas outras propriedades, o que mostra um afastamento progressivo na longa na duração, por exemplo, para o setor da rua Buisson (figura II, figura I2). De uma residência frequente no imóvel possuído no século XVII, passa-se, no meio do século XIX, a um afastamento num outro bairro. Esse distanciamento foi, sem sombra de dúvida, um potente fator de segregação social, por dissociação do lugar de residência entre proprietários e inquilinos. Nessa lógica, o imóvel não é mais que um bem capitalista a dar frutos, desligado de qualquer apego familiar ou pessoal. Eis aqui outro aspecto das evoluções de longa duração que aparecem quando comparamos as situações em datas distantes. Uma dessas evoluções muito marcantes é a dos trabalhadores da seda, examinada anteriormente.

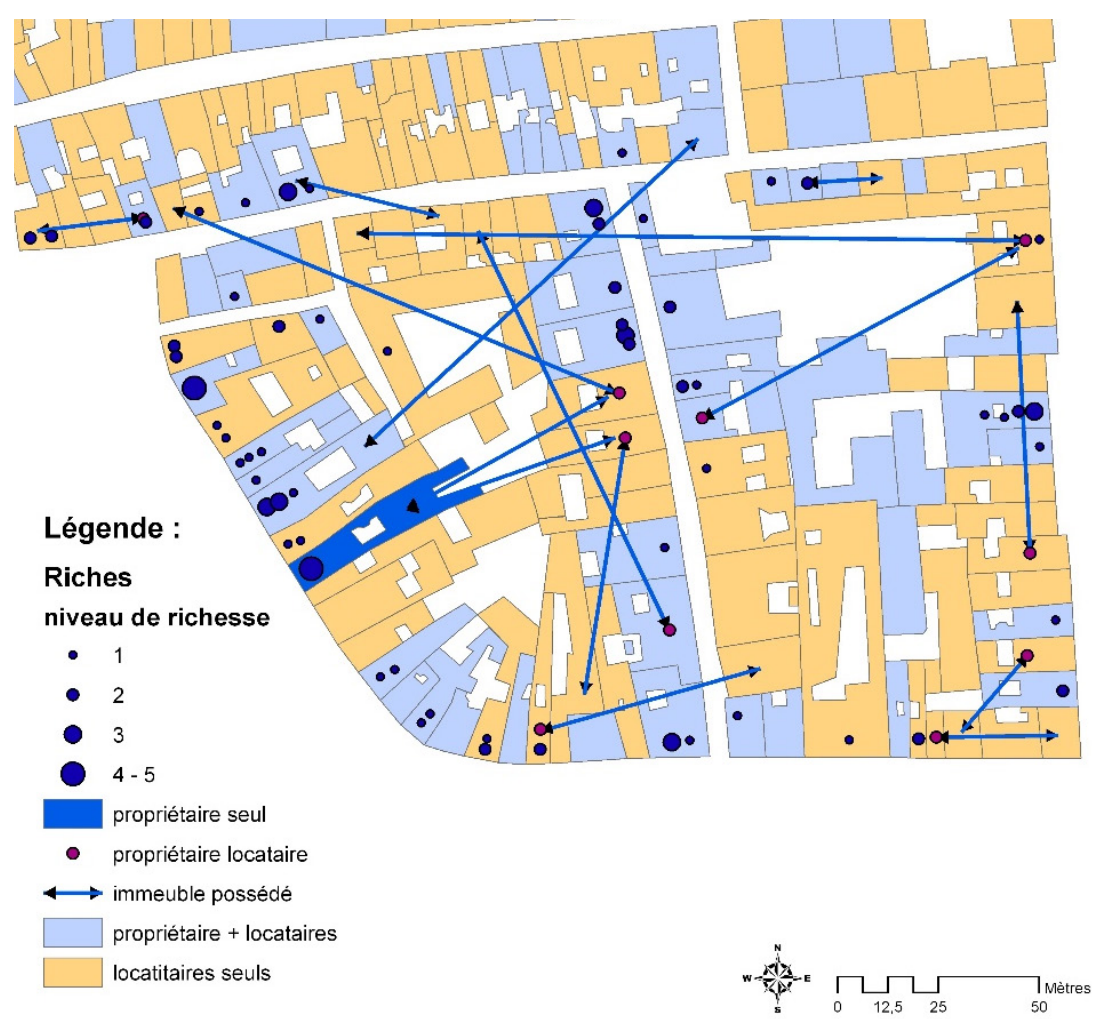

Figura II - Mapa da relação dos proprietários e seus imóveis, bairro da rua Buisson, situação em I677. Os proprietários que residem fora do perímetro não são indicados (B. Gauthiez@20I6)

4I RAU, Susanne; ZELLER, Olivier. Police des voyageurs et hospitalité urbaine à Lyon à la fin du XVIIe siècle. In BURKARDT, A. (Ed.). Commerce, voyage et expérience religieuse (Europe, XVIe-XVIIIe siècles). Rennes: Presses Universitaires, 2007. 


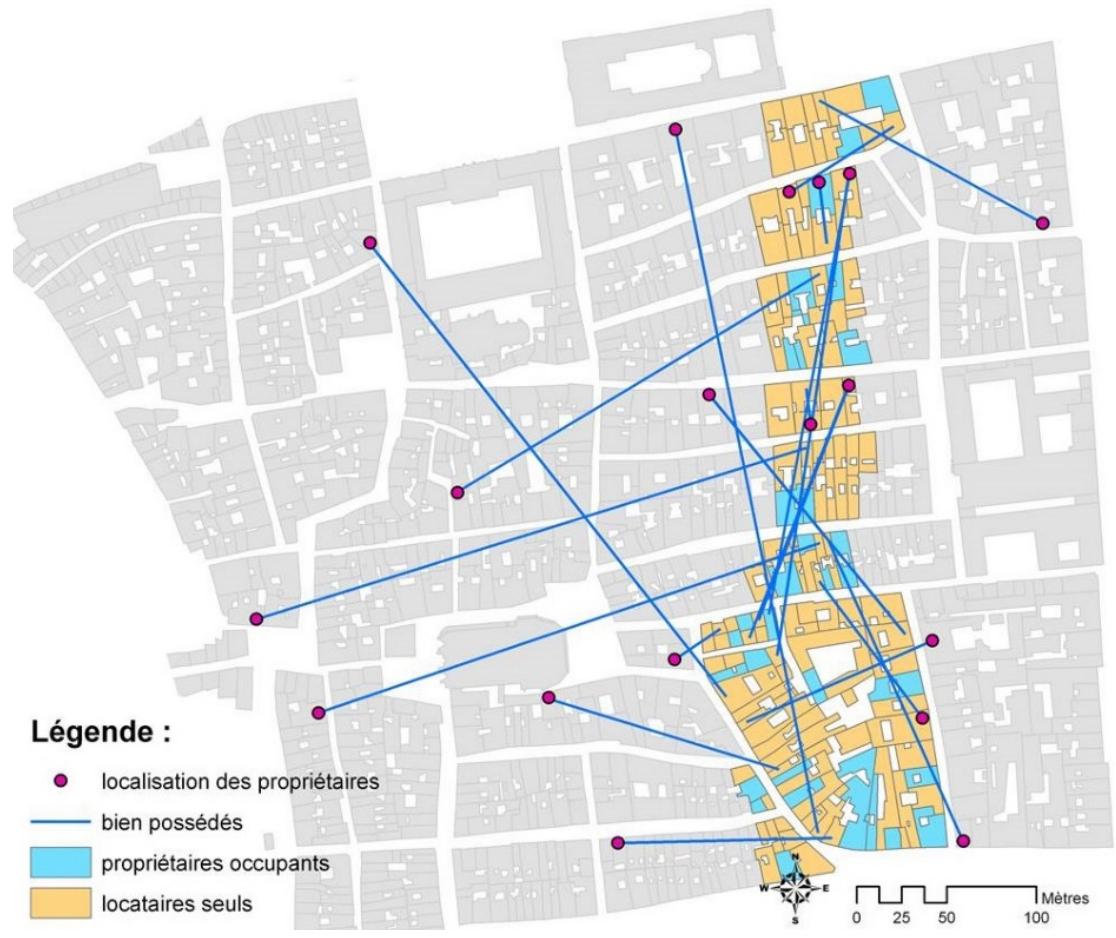

Figura I2 - Mapa da relação dos proprietários e seus imóveis, imóveis destinados a ser destruídos para a rua de la Republique, da rua Buisson, situação em I853. Os proprietários que residem fora do perímetro não são indicados (B. Gauthiez@20I6).

Obviamente, passar para a análise de uma cidade inteira, da escala do bairro ${ }^{42}$ à dos imóveis, necessita de um investimento considerável, que é também a extensão de uma micro-história para a cidade. Isso pode parecer paradoxal, mas trata-se, certamente, de uma dilatação da gama das escalas de estudos de uma mesma cidade, um conhecimento muito detalhado que pode ser generalizado (no sentido geográfico, que significa simplificado para uma forma a uma escala menos fina), sendo conservadas as escalas tradicionais de estudos. É necessário, também, notar que os estudos por bairros frequentemente são baseados em registros unitários por imóveis, e que a sua cartografia, precisamente por bairro, reflete a dificuldade para

42 CONCINA, Ennio. Venezia nell'età moderna, Struttura e funzioni. Venise: Marsilio, I984; CHAUVARD, Jean-François. Scale di osservazione e inserimento degli stranieri nello spazio veneziano tra XVII e XVIII secolo. In: Calabi, D.; Lanaro, P. (Ed.). La citta italiana e i luoghi degli stranieri, XIV-XVIII secolo. Rome-Bari: Laterza, I998, p. 85-I07; CHAUVARD, Jean-François. La circulation des biens à Venise, stratégies patrimoniales et marché immobilier (I600-I750). Rome: Ecole Française de Rome, 2005. 
localizar de forma precisa esses imóveis, enquanto o contorno dos bairros é mais fácil de reconstituir quando ele já não é simplesmente dado por mapas antigos.

A utilização de dados de mais de dois séculos para Lyon, no estado atual das nossas pesquisas, foi também necessária porque os arquivos da cidade não conservaram, com exceção das licenças de construção, séries de dados por ano, como, por exemplo, as séries fiscais (que subsistem para outras cidades). Era a única maneira de fazer aparecer as tendências, a escala cronológica das transformações espaciais e as suas lógicas, os "ciclos" econômicos de alguns anos, as grandes crises, numa palavra, a longa duração (figura I3).

House building in Lyon (1617 - 1827)

80

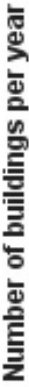

60

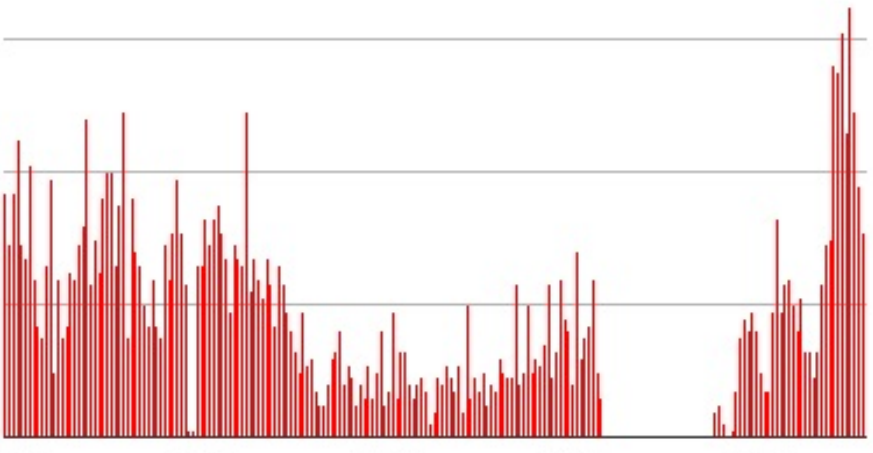

1620

1665

1710

1755

1800

Years

Figura 13 - Diagrama do número de licenças de construção autorizadas por ano, de I6I7 a I828, mostrando as temporalidades das variações do investimento imobiliário, anual, cíclico (5-8 anos), sobre a longa duração. A longa depressão da primeira metade do século XVIII é muito marcante, assim como o forte desenvolvimento posterior a I8I5. Faltam os dados para I763-I789, mas a tendência era fraca (B. Gauthiez@20I6)

Essa utilização do SIG faz emergir um novo paradigma de pesquisa. A espacialidade do espaço urbano e dos fenômenos geográficos urbanos não é mais restrita às escalas de uma cidade inteira e seus bairros. Do mesmo modo, as fontes seriais tratadas diacronicamente permitem ultrapassar o "momento" determinado por uma fonte única, o mapa estabelecido a tal data, o papel dos impostos ou do recenseamento. Os fatos reais são demasiado complexos para serem reduzidos a tais generalizações e simplificações, ainda que possam constituir etapas na abordagem da complexidade. O método aqui descrito permite desconstruir essa complexidade. O espaço urbano não é isomorfo, e deve ser estudado à escala relevante dos acontecimentos que o transformam ou o afetam. Também não é fixo e cognoscível somente em determinadas datas. Ele não é um dado que se localize em uma tabela dos fenômenos, mas uma matéria cuja transformação pelos seus habitantes e investidores 
varia no tempo e no espaço, uma matéria histórica por si mesma, como as licenças de construção mostram perfeitamente. Isso certamente implica a multiplicação por um fator de ordem de roo das unidades espaciais utilizadas para a cartografia (do bairro ao imóvel, no caso de Lyon), para novos e confiáveis resultados, que podem ser cruzados no SIG e capitalizados pela cartografia de cada nova fonte de dados, num sistema de informações perene.

Contudo, a cartografia não pode ser um objetivo em si mesma. Mas considerar um mapa como uma simples ilustração de um discurso escrito é ingênuo e procede de uma incompreensão. Do mesmo modo, transferir mecanicamente dados pré-construídos para um mapa não é um bom método ${ }^{43}$, porque nenhuma desconstrução dos dados foi realizada para concordar com a escala espacial dos fenômenos ou com sua natureza espacial. A dialética dos mapas e do texto deve ser concebida num outro nível. A localização precisa é uma informação essencial, é a única maneira de contextualizar os valores fundiários, os usos das construções, as estruturas arquiteturais e mesmo a sua decoração. É também um meio para reunir muitas informações isoladas, dispersas nas fontes escritas, cujo sentido permanecerá obscuro enquanto não forem reunidas e vinculadas a uma data e um lugar precisos e cruzadas com informações de outra natureza. A cartografia dinâmica e diacrônica permite particularizar esse

43 A utilização dos mapas antigos, a partir de um documento original em papel, segue, na historiografia, as etapas seguintes para chegar a um documento completamente informatizado: I) elementos gráficos, pontos, símbolos, linhas, polígonos, colocados sobre um mapa no formato raster (um documento escaneado). Não há necessidade de SIG nessa fase, um software de DAO é suficiente. Exemplos: LE ROUX, Thomas. La mise à distance de l'insalubrité et du risque industriel en ville. Le décret de I8Io mis en perspective (I760-I840). Histoire \& mesure, XXIV-2, 2009, p. 3I-70, figura 8; VITALI, Stefano. Dall documento alla risorsa: qualche riflessione metodologica selle fonti storiche nell'era digitale. In: PANZERI, Matteo; FARRUGGIA, Angela. (Ed.). Fonti, metafonti e GIS per l'indagine della struttura storica del territorio: verso il networking. Turin: Celid, 2009, p. I3-I6; p. I09-IIO; 2) elementos gráficos, pontos, linhas, polígonos, lugares sobre um mapa sob forma vetorial feita a partir de um documento antigo em papel, utilizando um software de CAD. Não há base de dados associada aos elementos localizados sobre o mapa. O mapa é um documento meramente analógico. Exemplo: BACKOUCHE, Isabelle. Mesurer le changement urbain à la périphérie parisienne. Les usages du Bassin de la Villette au XIXe siècle. Histoire er mesure, XXV-I, 20Io, p. 47-86, figuras 2, 3, I3; 3) elementos gráficos, pontos, linhas, polígonos, lugares sobre um mapa sob forma vetorial feita a partir de um documento antigo em papel, utilizando um software de CAD. Os elementos cartografados são proporcionais de acordo com um dado procedente de uma base de dados. O mapa final é, ainda, em parte, analógico. Exemplos: DAMASCENO FONSECA, Claudia. Comment mesurer les écarts entre les degrés d'urbanité et les titres urbains? Le cas des villes coloniales portugaises du Minas Gerais (Brésil, XVIIIe-début XIXe siècle). Histoire \& mesure, XXIV-2, 2009, p. I09-I46, figura; MARRAUD, Mathieu. Permanences et déplacements corporatifs dans la ville. Le corps de l'épicerie parisienne aux XVIIe-XVIIIe siècles. Histoire e mesure, XXV-I, 20IO, p. 3-45; 4) idem, com georreferenciamento do mapa raster utilizado em fundo de planta. Exemplo: BENTAYOU, Gilles; BENBOUZID, Bilel. L'urbanisme et ses études. Réflexions à partir de deux exemples de politiques d'aménagement urbain à Lyon. Histoire er mesure, XXIV-2, 2009, p. 7I-I08; 5) idem, mapa utilizado em fundo de planta constituído de uma ou várias camadas (layers) que associam, de forma vetorizada, os objetos geográficos acompanhados de dados, por exemplo, os polígonos para as parcelas e as construções, as linhas para as ruas. Aqui não existe mais a relação direta entre um mapa histórico de papel e o suporte cartográfico utilizado. O mapa é completamente digital. Exemplos: os mapas deste artigo. 
cruzamento. Compare-se isso a uma estrutura têxtil - os fios da trama são feitos dos dados sincrônicos, recenseamentos, listas de impostos...; os fios da cadeia são constituídos de dados diacrônicos, licenças de construção, mutações fundiárias, mudanças de uso... A cartografia diacrônica cruzada mostra a lógica compartilhada das transformações de naturezas diferentes. Os comportamentos imobiliários ${ }^{44}$, a transmissão e a transformação dos valores imobiliários ${ }^{45}$ podem ser eficazmente estudados de acordo apenas com uma espacialização precisa, que permite a interação entre o mapa e o texto, as fontes cartográficas e as fontes escritas.

\section{SOBRE O AUTOR}

BERNARD GAUTHIEZ é professor de Geografia-Planejamento da Faculdade de Artes e Civilizações da Université Jean Moulin Lyon III. Centre National de la Recherche Scientifique/UMR 5600 Environnement, Ville, Société.

E-mail: bernard.gauthiez@gmail.com

\section{REFERÊNCIAS BIBLIOGRÁFICAS}

BACKOUCHE, Isabelle. Mesurer le changement urbain à la périphérie parisienne. Les usages du Bassin de la Villette au XIXe siècle. Histoire er mesure, XXV-I, 20IO, p. 47-86.

BENTAYOU, Gilles; BENBOUZID, Bilel. L'urbanisme et ses études. Réflexions à partir de deux exemples de politiques d'aménagement urbain à Lyon. Histoire er mesure, XXIV-2, 2009, p. 7I-I08.

BOUDON, Françoise et al. Système de l'architecture urbaine, le quartier des halles à Paris. Paris: Centre National de la Recherche Scientifique, I977.

CABANTOUS, Alain. Histoire de la nuit. Paris: Publications de la Sorbonne, 2008.

. Le quartier, espace vécu à l'espace moderne. In: Histoire, economie et société, 3, I994, p. 427-440.

CABESTAN, Jean-François. La naissance de l'immeuble d'appartements à Paris sous le règne de Louis XV. In: RABREAU, Daniel. (Éd.). Paris, capitale des arts sous Louis XV. Bordeaux: William Blake and co/ Arts and Arts, I997, p. I67-I95.

CHAUVARD, Jean-François. Scale di osservazione e inserimento degli stranieri nello spazio veneziano tra XVII e XVIII secolo. In: CALABI, D.; LANARO, P. (Éd.). La citta italiana e i luoghi degli stranieri, XIV-XVIII secolo. Rome-Bari: Laterza, I998, p. 85-I07.

. La circulation des biens à Venise, stratégies patrimoniales et marché immobilier (I600-I750). Rome: Ecole Française de Rome, 2005.

CLAVAL, Paul; CLAVAL, Françoise. Cahors au milieu du XVIIe siècle et la géographie sociale de la ville préindustrielle. In: CLAVAL, Paul. (Éd.). Géographie historique des villes d'Europe occidentale, II - Espaces

44 CHAUVARD, Jean-François, op. cit., 2005.

45 LEPETIT, Bernard. The pre-industrial Urban System: France I740-I840. Cambridge, University Press I994. 
sociaux et paysages urbains. Paris: Publications du Département de Géographie de l'Université de Paris-Sorbonne n. I4, I977, p. 69-72.

CNRTL - Centre National de Resources Textuelles et Lexicales. Disponível em: http://www.cnrtl.fr/definition/censives. Acesso em: 20 fev. 2016.

CONCINA, Ennio. Venezia nell'età moderna, Struttura e funzioni. Venise: Marsilio, I984.

DAMASCENO FONSECA, Claudia. Comment mesurer les écarts entre les degrés d'urbanité et les titres Iurbains? Le cas des villes coloniales portugaises du Minas Gerais (Brésil, XVIIIe-début XIXe siècle). Histoire er mesure, XXIV-2, 2009, p. I09-I46.

FERRAND, Nicolas. Approche morphologique de l'urbanisation: Lyon et son agglomération de 1945 à 2005 , données, outils et méthode. Thèse (Doctorat de Géographie). Lyon: Université de Lyon Jean-Moulin, 2010.

GARDEN, Maurice. Lyon et les Lyonnais au XVIIIe siècle. Paris: Les Belles Lettres, I970

GAUTHIEZ, Bernard. Lyon, formation et évolution d'un espace urbain, I.- cartographie du site et Moyen-Âge. Vaulx-en-Velin: Ecole Nationale Supérieure d'Architecture de Lyon, I993.

. Espace urbain, vocabulaire et morphologie. Paris: Editions du Patrimoine, 2003.

. Des unités pertinentes pour mesurer la ville concrète. Histoire er mesure, XIX/3-4, 2004, p. 295-3I6. . The history of urban morphology. Urban morphology, 8(2), 2004, p. 7I-89.

. Lyon en I824-32: un plan de la ville sous forme vecteur d'après le cadastre ancien. Géocarrefour 83-I, 2008, p. 57-67.

. Typologie architecturale et démographie. L'habitat collectif à Lyon à l'époque moderne, I500-I800. In: GRENET, Mathieu; JAMBON, Yannick; VILLE, Marie-Laure. (Dir.). Histoire urbaine et sciences sociales. Mélanges en l'honneur du professeur Olivier Zeller. Paris: Garnier, 2014, p. I9-48.

GAUTHIEZ, Bernard; ZELLER, Olivier. Lyon aux XVII-XVIIIe siècles, la fabrique de la ville. In: BAJOLET, E.; MATTEI, M.-F.; RENNES, J.-M. (Éd.) Quatre ans de recherche urbaine 200I-2004. Tours: Presses Universitaires François-Rabelais/Maison des Sciences de L'homme, 2006, v. I, p. 459-463

Ordre textuel et ordre spatial à Lyon à l'époque moderne. Du parcours de visite au rôle nominal, une spatialité implicite. Histoire er mesure XXV-I, 20I0, p. I97-230.

Le dédommagement des reculements: un instrument de la politique d'aménagement urbain à Lyon aux XVIIe et XVIIIe siècles. Histoire er mesure, XXVIII-I, 2013 p. 45-73.

GREGORY, Ian N. A place in history: a guide to using GIS in historical research. Oxford and Oakville: Oxbow Books, 2003.

GREGORY, Ian N.; ELL, Paul S. Historical GIS: techniques, methodologies and scholarship. Cambridge: Cambridge University Press, 2007.

JUNOT, Yves. Mixité sociale, habitat et propriété: la paroisse Saint-Jacques de Valenciennes en I602 d'après un registre du centième. Revue du Nord, LXXIX, I997, p. 4I3-427

LE ROUX, Thomas. La mise à distance de l'insalubrité et du risque industriel en ville. Le décret de I8IO mis en perspective (I760-I840). Histoire er mesure, XXIV-2, 2009, p. 3I-70.

LEPETIT, Bernard. The pre-industrial urban system: France I740-I840. Cambridge: Cambridge University Press, I994.

MARRAUD, Mathieu. Permanences et déplacements corporatifs dans la ville. Le corps de l'épicerie parisienne aux XVIIe-XVIIIe siècles. Histoire er mesure, XXV-I, 20Io, p. 3-45.

MICHEL, Henri. Urbanisme et société à Montpellier sous l'Ancien régime. Un exemple: le sixain SaintFirmin (I665-I756). Annales du Midi, II6, I974, p. 2I-43.

PASCAL, C. Bipolarisation sociale dans la ville d’Ancien Régime. Le sixain Sainte-Croix de Montpellier, I665-I788. Revue d'histoire moderne et contemporaine, 4I-43, I994, p. 395-4I7. 
JUNOT, Yves. Mixité sociale, habitat et propriété: la paroisse Saint-Jacques de Valenciennes en I602 d'après un registre du centième. Revue du Nord, LXXIX, I997, p. 4I3-427.

RAU, Susanne; ZELLER, Olivier. Police des voyageurs et hospitalité urbaine à Lyon à la fin du XVIIe siècle. In: BURKARDT, A. (Ed.). Commerce, voyage et expérience religieuse (Europe, XVIe-XVIIIe siècles). Rennes: Presses Universitaires, 2007.

SCHÄTTI, Nicolas; VIACCOZ DE NOYERS, Anne-Marie. L’Atlas historique de la ville de Genève, vieilles méthodes, nouveaux outils. Patrimoine et architecture I4-I5, 2005, p. 58-64.

SODEZZA, Guillaume. Vers un atlas morphogénétique de la vallée du Giers. Caractérisation des éléments et structures matérielles hérités. Thèse (Doctorat de Géographie). Lyon: Université de Lyon Jean-Moulin, 20I4.

VITALI, Stefano. Dal documento alla risorsa: qualche riflessione metodologica selle fonti storiche nell'era digitale. In: PANZERI, Matteo; FARRUGGIA, Angela. (Ed.). Fonti, metafonti e GIS per l'indagine della struttura storica del territorio: verso il networking. Turin: Celid, 2009, p. I3-I6; p. I09-IIO.

ZELLER, Olivier. Géographie des troubles et découpage urbain à Lyon (XVIème-XVIIIème siècles. In: CONGRÈS DES SOCIÉTÉS SAVANTES, II4. Paris, I989. Les espaces révolutionnaires. Paris: Editions du Comité des Travaux Historiques et Scientifiques, I990, p. 43-59.

ZELLER, Olivier. Espace privé, espace public et cohabitation. Lyon à l'époque moderne. In: HAUMONT, Bernard; MOREL, A. (Éd.). La société des voisins, partager un habitat collectif. Paris: Editions de la Maison des Sciences de l'Homme, 2005, p. I87-207. 